\title{
SOBRE LA ASISTENCIA A VÍCTIMAS DE DELITOS MÁS ALLÁ DEL ESTATUTO DE LA VÍCTIMA ${ }^{1}$
}

\author{
Paz Mercedes de la Cuesta Aguado²
}

Resumen: La asistencia a las víctimas de delitos presenta aspectos que escapan a la genérica regulación legal o reglamentaria y que son propiamente cuestiones de organización, planificación e, incluso, de intendencia. Este artículo trata de sugerir medidas que faciliten la relación de las víctimas con el sistema judicial penal, que eviten la revictimización y nuevos procesos de victimización primaria y que mejoren la calidad de vida de las víctimas y su percepción del sistema penal. Para ello se diferencian varios "grupos de víctimas de delitos", dependiendo de los efectos de sus procesos de victimización, con la finalidad de sugerir medidas especialmente adecuadas para ellas, en un intento de poner de manifiesto la necesidad de superar la sectorialidad de la asistencia que se centra, sobre todo, en algunos grupos de víctimas, así como la

\section{Recibido: abril 2019. Aceptado: mayo 2019}

1 Investigación realizada en el Proyecto de Investigación DER2016-77228-P.

2 Categoría profesional. Catedrática de Derecho penal. ORCID 0000-00015738-3776

Departamento de Derecho público de la Facultad Derecho. Universidad de Cantabria. Dirección Avda. De los Castros s/n, 39005, Santander. E-mail: cuestapm@unican.es 
desigual distribución territorial de las Oficinas de Asistencia a las víctimas (OAV).

Palabras clave: Víctima, Oficina de Atención a las víctimas, delitos, violencia, género.

\title{
ON SUPPORT TO VICTIMS OF CRIMES BEYOND THE STATUTE OF VICTIMS OF CRIMES
}

\begin{abstract}
The assistance to victims of crime has many aspects that escape legal or regulatory regulation and that are properly matters of organization and planning. For better assistance to victims, we suggest measures that facilitate victims' access to the criminal justice system, to avoid revictimization (secondary victimization) and to avoid new processes of primary victimization. All this in order to improve the quality of life of the victims and their perception of the penal system. For this, we will distinguish between "groups of victims of crime" depending on the effects they suffer as a result of their victimization processes. Afterwards, we suggest suitable measures especially designed for them. But we warn that a correct assistance of the victims needs to overcome the sectoriality of the assistance that is centered, above all, in some groups of victims and the unequal territorial distribution.
\end{abstract}

Key Words: Victim, Support Offices, crime, violence, gender.

\section{Cuestiones introductorias y precisiones terminológicas}

I. En una sociedad inserta en movimientos populistas con tendencias centrífugas, no solo en lo territorial sino, sobre todo, en lo ideológico, el sistema jurídico-penal ha de reforzar su papel racionalizador en la respuesta social frente al delito; y una parte importante de este sistema penal es la asistencia que se ofrece a las víctimas. La cultura de la victimidad demanda del Estado respuesta suficiente a la vulneración de la ley penal -el delito-y satisfacción a las víctimas, como manifestación del sentimiento de Justicia. La exigencia de protección de las víctimas, en ocasiones, se trata de satisfacer mediante la incorporación de nuevos delitos en las leyes penales; delitos que, también en ocasiones, exceden la racionalidad del sistema penal democrático 
para entrar en un nuevo modelo de Derecho penal sentimental, en el que los sentimientos, las subjetivas microagresiones y las emociones pugnan por hacerse hueco.

Esta demanda de la cultura de la victimidad, que exige la incorporación de cada vez más delitos que protejan sentimientos $o$ percepciones subjetivas de agresiones o daños, es una consecuencia de la incapacidad del Estado para hacer frente a la demanda primigenia: la de la satisfacción de las necesidades de las víctimas. De ahí la enorme importancia de arbitrar un sistema de asistencia a las víctimas completo, satisfactorio, racional, bien organización, extenso y cercano al ciudadano, que no discrimine por razón del territorio -en perjuicio de la España vacía-. Pues solo se puede evitar el autoritario Derecho penal de los sentimientos si estos -los sentimientos, las necesidades de las víctimas- se satisfacen mediante medidas asistenciales. Lo contrario representa una quiebra de los principios básicos del control de la violencia estatal ejercida por un Derecho penal democrático y, como consecuencia una quiebra del propio sistema democrático $\mathrm{y}$, además, realmente, ni protege ni asiste a las víctimas -o sea, es inútil-. Pero ello exige conocimiento, racionalidad y medios. Por ese orden.

II. Desde el año $2015^{3}$, la asistencia a las víctimas de delitos, en España, ha recibido un fuerte impulso con la aprobación de la Ley 4/2015, de 27 de abril, del Estatuto de la víctima del delito; del Real Decreto 1109/2015, de 11 de diciembre ${ }^{4}$, por el que se desarrolla la ley anterior y, aunque en un ámbito sectorial,

3 Desde finales del siglo pasado, la Doctrina ha ilustrado con profusión un creciente movimiento de interés por las víctimas de delitos y, especialmente, de interés por las víctimas de determinados delitos; interés que se ha materializado, por un lado, en la aparición de normas destinadas a proteger a las víctimas y a facilitar la "desvictimización" y, por otro lado, en la aparición, formal, mediante textos normativos, o informal, en el ámbito político o de la opinión pública, de catálogos de "derechos de las víctimas".

4 Un resumen en inglés puede encontrarse disponible en https://e-justice. europa.eu/content_rights_of_victims_of_crime_in_criminal_proceedings171-ES-maximizeMS-en.do?clang $=$ en\&idSubpage $=9 \&$ member $=1 \quad$ [citado:15.01.2019]. 
del Real Decreto-ley 9/2018, de 3 de agosto, de medidas urgentes para el desarrollo del Pacto de Estado contra la violencia de género ${ }^{5}$. Estas normas impulsan $\mathrm{y}$, sobre todo, visibilizan y extienden las normas y formas correctas de asistencia y atención a víctimas de delitos en los "ámbitos jurídico, psicológico y social" y determinan los objetivos y funciones, entre otras cuestiones, de la Oficinas de Atención a las Víctimas (OAV). No es, sin embargo, esta asistencia la que nos va a ocupar, sino otras fórmulas de asistencias a las víctimas de delitos que también buscan facilitar las relaciones de las víctimas con la Justicia penal e, incluso, prevenir nuevos procesos de victimización futuros, sin un gran coste añadido y que, además de incidir en los mismos fines, coadyuvan a la "salvaguarda integral de la víctima", finalidad expresa del Estatuto de Víctima del delito -en términos de su Exposición de Motivos-.

Pese al esfuerzo normativo -y económico-, el actual modelo de protección y asistencia a las víctimas de delitos no ha estado exento de polémica ${ }^{6}$. Por un lado, se ha advertido que "la mayoría de la lucha por los derechos de las víctimas ha estado lejos de ser desapasionada y [...] tiene una marcada tendencia conservadora" y simbólica ${ }^{7}$ y que puede ir acompañada

5 Críticamente sobre dicho Pacto, puede verse VILLACAMPA ESTIARTE, C.: "Pacto de estado en materia de violencia de género: ¿más de lo mismo?", en $R E C P C$ 20-04 (2018), 2 jun, pp. 1-38. Disponible en http://criminet.ugr. es/recpc/20/recpc20-04.pdf [citado: 20.02.2019].

6 La protección de las víctimas, además, no ha sido uniforme, sino que la protección, en España se ha ido haciendo de forma sectorial -y, parcialmente, así sigue- hasta que el Estatuto de la Víctima ha procurado homogeneizar y equiparar los derechos de todas las víctimas de delitos en función de sus necesidades y vulnerabilidades y no ya en función del delito que diera lugar a su concreto proceso de victimización.

7 En cuanto que la idea de "víctima" evoca una imagen de inocencia, "de estereotipo puro e irreprochable", que permite que los ciudadanos se identifiquen con ellas, lo que tiene un enorme poder de movilización social. En este sentido, también HENDERSON, L.: "The Wrong's of Victim's Rights", Las Vegas, 1985, p. 951. Disponible en https://scholars.law.unlv.edu/cgi/ viewcontent.cgi?article=1894\&context=facpub [citado:14.08.2018], p. 951 .

Estudios Penales y Criminológicos,

vol. XXXIX (2019). ISSN 1137-7550: 403-454 -406- hitp://dx.doi.org/10.15304/epc.39.5970 
por una limitación o reducción de los derechos del acusado ${ }^{8}$. Sin embargo, estas acusaciones solo parcialmente son aplicables a nuestro Ordenamiento Jurídico, ya que los derechos de las víctimas nunca han estado (absolutamente) excluidos del proceso penal -al menos en lo que se refiere a sus intereses económicos-. Por lo demás, la protección, hasta 2015, ha sido marcadamente sectorial y, en los últimos tiempos, haciéndose eco de tales críticas, aunque por motivos diversos, algunos partidos políticos proponen reducir la protección a determinados grupos de víctimas $^{9}$ con la excusa de que la cada vez mayor protección de las víctimas exacerba la intervención penal, quiebra el principio de igualdad y limita los derechos de los acusados. Y, simultáneamente, se reclama constantemente que se incrementen las penas y se utiliza a las víctimas (de violencia terrorista, de violencia de género, "de abortos" ...) para movilizar a los ciudadanos y para evitar los argumentos racionales y limitadores del Ius Puniendi.

Pero, quizá la más importante de las críticas es la que pone su acento en la existencia de déficits en la protección a las víctimas. Entre las posibles carencias del actual modelo de protección de las víctimas de delitos, cabe destacar las limitaciones en la asistencia derivadas de la sectorialización de la que, al menos hasta ahora, adolece, así como la desigual implementación territorial de las medidas de asistencia y apoyo, junto a la ausencia de otras modalidades de asistencia, orientadas a evitar nuevos procesos de victimización primarios y a facilitar las relaciones de las víctimas con la Administración de Justicia, pero no desde una perspectiva estrictamente procesal o jurídica.

8 HENDERSON, L.: "The Wrong's of Victim's Rights", cit., p. 967, en relación con esta cuestión enumera los siguientes: 1) detención, en todo caso y prisión preventiva después de la detención; 2) agilización mediante la limitación de plazos y requisitos formales de los trámites procesales; 3 ) limitación a las conformidades y acuerdos procesales sobre la culpabilidad de acusado o que esta dependa de la voluntad de la víctima; 4) exclusión del acusado del interrogatorio a las víctimas y, 5) exclusión o limitación en la apreciación de atenuantes y eximentes, lo que invita a la autora a afirmar que todo ello parece más pensado para incrementar el "control del crimen" que para socorrer a las víctimas.

9 En concreto, de víctimas de violencia de género, por razones ideológicas. 
Serán estas cuestiones, precisamente, el objeto de nuestra reflexión: la asistencia a las víctimas más olvidadas -las que están al margen de los núcleos de interés en la protección. Y lo vamos a hacer desde una perspectiva, en cierta medida, ajena a la del Estatuto de Víctima, incidiendo en la asistencia y apoyo en cuestiones de intendencia y preventivas. No podremos, sin embargo, detenernos a analizar el problema de la desigual implementación territorial de la asistencia a las víctimas de delitos, cuestión que viene condicionada, en un primer momento, por la organización territorial de la Administración de Justicia e incrementado por la aún escasa implantación de OAV y, después, por la tendencia a ceder la asistencia solo o primordialmente a ellas (OAV). Pensamos, sin embargo, que es preciso alertar contra la atomización de la asistencia a las víctimas en las OAV, entre otras razones porque, entonces, tendrían dificultades para llegar a todas las víctimas o, al menos, hacerlo en igualdad de condiciones. En este sentido sería muy interesante (incluso necesario) arbitrar modelos que permitan que en cada sede judicial exista, al menos, un punto de referencia de atención a víctimas de delitos, bien dependiente de una OAV, bien, en coordinación con ella, dependiente del propio juzgado o instancia judicial.

III. Intentando no caer en la sectorialización, vamos a abordar el estudio de las necesidades de las víctimas de delitos, en función de las necesidades derivadas de los diversos procesos de victimización; necesidades que dependen, en cierta medida, del delito padecido, sin perjuicio de que existan necesidades comunes. Por otro lado, no está de más definir, aunque no sea con límites rígidos, los grupos de víctimas que reúnen características comunes -en función de los delitos padecidos-. A estos efectos sugerimos a continuación un catálogo de "grupos de víctimas" que no pretende ser ni cerrado, ni exhaustivo, pero que nos permite mostrar la diversidad de situaciones en que se encuentran las víctimas de delitos y la complejidad -por la diversidad- de los propios grupos. Todo ello, por supuesto con la finalidad de intentar profundizar en la asistencia de las víctimas. 
1.- Víctimas de delitos que implican violencia o intimidación -lo que generalmente se denomina (mal) "víctimas de delitos violentos". Dentro de este grupo, presentarían características especiales, las víctimas del terrorismo, los funcionarios víctimas de violencia o intimidación en el ejercicio de sus funciones y las víctimas de violencia de doméstica y de género.

2.- Víctimas de delitos contra el patrimonio de las personas.

3.- Víctimas de delitos cometidos utilizando tecnologías de la información.

4.- Víctimas de delitos contra la seguridad vial.

5.- Víctimas de delitos relacionados con el incorrecto funcionamiento de la Administración Pública y la Administración de Justicia.

Junto a las anteriores, pero sin poder detenernos ahora en ellas, hay que tener en cuenta que, además, en función de las características personales de las víctimas, surgirían nuevas especialidades que deberían ser tenidas en cuenta para arbitrar una correcta asistencia. En este sentido, habría que prever medidas específicas para menores; víctimas especialmente vulnerables; ancianos; drogodependientes relacionadas con sus propios delitos de tráfico de drogas o extranjeros, al menos.

Resulta realmente difícil obtener datos acerca de las víctimas de delitos y sus características, por lo que acudiremos a fuentes de diverso origen. En un primer momento, como una mera aproximación partiremos de los datos sobre delincuencia en España publicados por el Instituto Nacional de Estadística, lo que nos podría ayudar a cuantificar la incidencia de tales procesos de victimización en función de las clases de delitos ${ }^{10}$. Pero,

10 Esta distinción puede ser importante porque todas las víctimas no tienen las mismas necesidades, sin perjuicio de que todas ellas tengan necesidades comunes. Así, HENDERSON, L.: "The Wrong's of Victim's Rights", cit., p. 955 afirma que los efectos psicológicos de todos los delitos y de las catástrofes naturales son los mismos, de lo que se derivaría que todas las víctimas que han sufrido una situación de riesgo personal necesitarían, en principio, 
también, utilizaremos las estadísticas y datos ofrecidos por las instituciones públicas del Estado, el CGPJ o del Gobierno de Cantabria correspondientes a los años 2016 y $2017^{11}$. La finalidad no es ofrecer una foto fija de la situación -imposible por la escasez de los datos, lo dispares que son los criterios de selección de estos y la ausencia de datos en algunos supuestos-, sino, reflexionar sobre el porqué y la forma de obtenerlos (los datos), así como sobre cómo mejorar la protección de las víctimas a partir de ellos ${ }^{12}$.

IV. El abandono de la violencia, la cultura de la victimidad, la extensión del modelo de Estado social y de los Derechos Humanos, así como la cada vez mayor atención que la Academia presta a la "víctima del delito", han contribuido a que este concepto haya traspasado las puertas del Derecho penal; un Derecho penal que busca renovar su legitimación, también, en la protección de las víctimas en pleno proceso expansivo en una sociedad cada vez más compleja. De este modo, el Código penal utiliza el término "víctima" para designar al sujeto pasivo o el objeto de la acción típica (cuando no coincidan) en delitos que protegen bienes jurídicos individuales ${ }^{13}$. Con ello se está refiriendo, por tanto, a la víctima directa de un delito; con lo que se está restringiendo el concepto "víctima de un delito" incorporado a textos

un tratamiento psicológico similar, adaptado posteriormente, por supuesto, a las necesidades del caso y de la persona afectada, pero sin que dependa de patologías previas.

11 Pueden verse en http://mujerdecantabria.com/wp-content/uploads/2018/01/ informe-Violencia-de-genero-Cantabria-2015.pdf [citado:18.08.2018] y 2016, http://mujerdecantabria.com/wp-content/uploads/2018/05/Violenciade-genero-Cantabria-2016.pdf [citado:18.08.2018].

12 Esta es la razón por la que los datos pueden parecer desactualizados cuanto este trabajo se publique con posterioridad, pero, pensamos que lo principal es contar con años en los que ya estén publicados y consolidados todos los informes, lo que no sucede, en el momento en que se cierra este artículo, con los datos de 2018.

13 Algunos delitos podrían plantear dudas doctrinales al respecto, por ejemplo, el art. 362 quinquies -delito de dopaje-. No obstante, el tipo penal exige la puesta en peligro de determinadas personas a las que denomina "víctimas" (art. 362.2. $1^{\mathrm{a}} \mathrm{CP}$ ). 
internacionales, como la Declaración sobre los principios fundamentales de justicia para las víctimas de delitos y de abuso de poder, de $1985^{14}$, la DIRECTIVA 2012/29/UE, de 25 de octubre, por la que se establecen norma mínimas sobre los derechos, el apoyo y la protección a las víctimas de los delitos, o, en nuestro ordenamiento jurídico, el del Estatuto de la Víctima ${ }^{15}$.

El concepto de víctima que utilizaremos aquí no ha de coincidir, necesariamente, con este, sino que lo utilizaremos en el sentido más amplio en el que se incluirán víctimas directas e indirectas, según el Estatuto de la Víctima, pero también otros perjudicados personalmente por el delito, ya sea en términos económicos o en su salud (física o psíquica), e, incluso, según el caso, a terceros familiares o convivientes que se ven perjudicados indirectamente por el delito padecido por un allegado.

\section{Víctimas de delitos que implican violencia o intimidación contra las personas}

\subsection{Sobre los conceptos de violencia o intimidación}

I. El Código penal español no define qué entiende por "violencia" y, de hecho, contiene significados distintos para el mismo término ${ }^{16}$. Así, según el precepto penal que define el de-

14 Así la Resolución 40/34 de 1985, de la Asamblea General de la ONU. Disponible en https://www.unodc.org/pdf/compendium/compendium_2006_ es_part 03_02.pdf [citado: 27.02.2019], que, en su primer artículo, extiende la condición de víctima a los supuestos en los que no exista denuncia o condena penal (independientemente de que se identifique, aprehenda, enjuicie o condene al perpetrador) y a los familiares o personas a cargo que tengan una relación inmediata con la víctima y a las personas que hayan sufrido daños al intervenir para asistir a la víctima en peligro o para prevenir la victimización; o la DIRECTIVA 2012/29/UE, de 25 de octubre, por la que se establecen norma minimas sobre los derechos, el apoyo y la protección a las víctimas de los delitos, que también, en su artículo $2^{\circ}$. incluye en el concepto de víctima del delito a diversos familiares y convivientes.

15 El Estatuto de la Víctima considera también "víctima" (indirecta) en los casos de muerte o desaparición de personas como consecuencia de un delito a algunos familiares.

16 Más ampliamente, véase SÁNCHEZ TOMÁS, J.M.: La violencia en el Derecho penal, ed. Bosch, Barcelona, 1999, pp. 943 ss. 
lito en concreto, por violencia se entenderá, en ocasiones, el uso de fuerza física contra una persona, para, en otras incorporar, en este concepto de violencia, la intimidación o la "violencia psíquica", en un proceso de extensión del concepto o "deslizamiento conceptual", aceptando la expresión de HASLAM ${ }^{17}$.

En este, en ocasiones incierto, panorama, el concepto de "violencia doméstica" o "violencia de género"18 presenta peculiaridades que lo alejan del concepto jurídico-penal tradicional de violencia. En primer lugar, el concepto de "violencia de género" -que convive con el de "violencia contra la mujer"- que se está utilizando en la sociedad y para estudios criminológicos es distinto al "concepto de violencia de género" que, hasta 2015 y como consecuencia de la modificación de Código penal efectuada por la LO 1/2004, de 28 de diciembre, de Medidas de Protección Integral contra la Violencia de Género, regía en el Código penal. Hasta ese momento "delitos contra la violencia de género" eran, básicamente, faltas que se elevaban a la categoría de delito cuando los sujetos pasivos eran determinadas personas del ámbito familiar, específicamente, las mujeres en una relación de pareja (actual o pasada) y el sujeto activo, el hombre. Sin embargo, la mayoría de los delitos que podían padecer las mujeres

17 HASLAM, N.: "Concept creep: Psychology's expanding concepts of harm and pathology", en Psychological Inquiry, n. 27, 2016, pp. 1-17.

18 Es preciso recordar, sin embargo, que la expresa referencia al género como "motivo" de la violencia solo aparece, inicialmente como un elemento de la tipicidad, en el art. 607 bis $1.1^{\circ}$ del Código penal, en el delito de Lesa Humanidad, según el cual "son reos de lesa humanidad, [...] quienes cometan los hechos por razón [...] de género. La LO 1/2004, de 28 de diciembre, de Medidas de Protección Integral contra la Violencia de Género, utiliza también un concepto sui generis de "violencia de género", que se incorpora al Código penal en los arts. 83, 84 y 88 Código penal. Posteriormente, la reforma de 2015 "generaliza" la referencia al "género" en la agravante genérica de art. 22.4 del Código penal y en algunos tipos en concreto, como, por ejemplo, en los denominados "delitos de odio" de los artículos $510 \mathrm{y}$ siguientes del Código penal. Puede verse, sobre la citada ley, LAURENZO COPELLO, P.: "La violencia de género en la Ley Integral. Valoración político-criminal", en RECPC 07-08 (2005), pp. 08:1- 08:23. Disponible en: http://criminet.ugr.es/recpc/07/recpc07-08.pdf [citado: 20.09.2018].

Estudios Penales y Criminológicos, 
por razón de género no eran, a efectos penales, delitos contra la violencia de género. Esta situación parece haber sido modificada tras la reforma de 2015 del Código penal, que introdujo en el artículo 22.4, en la agravante por discriminación, la referencia expresa al género -aunque ya existía una referencia expresa al sexo, que no se venía aplicando-. Esta nueva situación hace pensar que, ahora, todos los delitos contra las personas se podrían cometer por razón de género, lo que cambia el panorama e invita a (re)pensar críticamente para qué sirven los delitos específicos contra la violencia de género, si ya tenemos una agravante genérica, $y$, sobre todo, cuál es el papel que quiere desempeñar el Derecho penal en la prevención y sanción de la violencia en el ámbito doméstico, porque no puede olvidarse que los "delitos contra la violencia de género" también lo son "contra la violencia doméstica".

En segundo lugar, es preciso desenmascarar la gran falacia que oculta el actual modelo de protección contra la violencia de género; falacia que está teniendo como consecuencia que algunos sectores estén criticando duramente por discriminatoria e ideológicamente condicionada la regulación penal y, por extensión, la protección a estas víctimas ofrecida por el Estado, lo que tiene graves y perturbadores efectos políticos, sociales y, sobre todo, de victimización social sobre la víctimas primarias de los delitos de maltrato. Efectivamente, algunos grupos o sectores de la sociedad, para los que el rol de las mujeres en esta sociedad no se ha desprendido de históricas connotaciones relacionadas con su primordial papel como hembras de la especie, pero que defienden, en el plano teórico, la igualdad ante la ley y que no siempre perciben que la igualdad formal es discriminación cuando la igualdad material no existe, rechazan por "ideológica" y discriminatoria la intervención penal y la protección y asistencia específica a mujeres víctimas de la violencia que ejercen sobre ellas sus parejas varones. Las reclamaciones de estos sectores no son nuevas ni ajenas a los tribunales penales, aunque por razones políticas, como consecuencia de la crisis democrática que padece España, está en estos momentos teniendo mayor repercusión. 
De hecho, los delitos específicos contra la violencia doméstica y de género, se introdujeron -de la forma en que se hizo en 1989para evitar absoluciones ante graves casos de maltrato habitual de la mujer en la pareja, generalmente, en aquellos momentos, en el matrimonio-. Pero, históricamente y todavía ahora, de hecho, siguen siendo utilizados para privilegiar al hombre en casos de violencia en la pareja -es decir, para imponerle menos pena que la que se le podría imponer si no existieran estos delitos-. Los ejemplos jurisprudenciales son numerosísimos, pero no nos podemos detener. Baste recordar, a estos efectos, las amenazas de muerte sancionadas como amenazas leves, los maltratos habituales sancionados como amenazas leves o el tratamiento jurisprudencial de las denominadas "peleas mutuas", que tanta controversia ha generado hasta la reciente sentencia del Pleno del Tribunal Supremo 677/2018, de 20 de diciembre ${ }^{19}$.

La falacia a la que venimos haciendo referencia en el párrafo anterior, también es utilizada para afirmar que "a los hombres se les castiga mucho más que a las mujeres por delitos idénticos", lo que, en relación con la intensidad es francamente falso: en ocasiones se sanciona un poquito más, pero, en otras muchas, se puede sancionar igual, y siempre, en principio, en relación con los delitos más leves -y eso, como en el caso de las peleas mutuas, cuando no se les ha castigado menos ${ }^{20}$. Todo lo anterior, podría cambiar rápidamente en función de cómo apliquen los tribunales la agravante de discriminación por género del artículo 22.4 del Código penal ${ }^{21}$.

19 La sentencia del Pleno de la Sala de lo Penal del Tribunal Supremo 677/2018, de 20 de diciembre que considera, que, en relación con el art. 153 del Código penal, la relación entre sujeto activo y pasivo ha de apreciarse de forma objetiva, sin "aditamentos subjetivos de prueba".

20 Véase, por todos, MANJÓN-CABEZA OLMEDA, A.: en Derecho penal español. Parte especial (I), de F.J. Álvarez García (Dir.), $2^{\mathrm{a}}$ ed., Valencia, 2011. cit., p. 493.

21 La posición mayoritaria en las Audiencias Provinciales y Tribunales Superiores de Justicia ha venido considerando que la agravante de discriminación por razón de género se aplicaba en los supuestos de violencia ejercida por un hombre sobre su pareja mujer actual o pasada. Sirva como ejemplo, la SAP Cantabria 204/2018, de 7 de junio, en relación con una tentativa de 


\section{Con independencia de lo anterior, el concepto de "vio-}

lencia" en relación con la denominada "violencia de género"

homicidio, que define y delimita el ámbito de aplicación de la agravante del art. 22.4 CP -"por razones de género"- en los siguientes términos: De este modo, la nueva circunstancia agravante será aplicable en todos aquellos casos en que el sujeto activo (siempre un varón) comete el delito motivado por el propósito de discriminar o de hacer patente la situación de desigualdad o la relación de poder sobre el sujeto pasivo (siempre una mujer que sea o haya sido su cónyuge, o que esté o haya estado ligada a él por relaciones similares de afectividad, aun sin convivencia). [...] no podría aplicarse en los delitos tipificados en los artículos 153, 171, 172 y 173.2 $C P,[\ldots]$ será incompatible con aquellos subtipos agravados en los que ya se contempla la "razón de género", como es el caso del artículo $148.4^{a}$ $C P, y$ los nuevos tipos penales regulados en los artículos 510, artículos 511 y artículos 512 CP (delito de discriminación). [...] no habrá lugar a la aplicación de esta circunstancia agravante, por así establecerlo el artículo 67 CP, siendo éste el caso de los delitos de amenazas para atemorizar a un grupo étnico (art. 170), discriminación en el empleo (art. 314), provocación a la discriminación contra grupos o asociaciones (art. 510), denegación de prestaciones (arts. 511 y 512), asociaciones ilicitas que promuevan la discriminación (art. 515.5 ) y delitos de genocidio (art. 607). Por las razones ya expuestas, esta agravante no sería de aplicación en los delitos de violencia en el ámbito doméstico o familiar (arts. $148.4^{\circ}, 153,171.4^{\circ}$, $172.2^{\circ}$ y $173.2^{\circ}$ ). Aunque también las STS 420/2018, de 27 de septiembre y la STS 565/2018, de 19 de noviembre, buscan una fundamentación subjetiva a la circunstancia agravante por razón de género ("concurrencia de intención, actitud o situación de dominación del hombre sobre la mujer -según la primera sentencia citada-; "matiz netamente subjetivo", en palabras de la segunda de ellas), la evolución de la doctrina del Tribunal Supremo ha sido rapidísima y ha venido forzada por la sentencia del Pleno de la Sala de lo Penal del Tribunal Supremo 677/2018, de 20 de diciembre -véase nota 19-. En nuestra opinión, la circunstancia agravante por razón de género del artículo 22.4 del Código penal, habrá de fundamentarse en razones objetivas, y no en meros sentimientos, intenciones o móviles, que siempre han de quedar fuera del Derecho penal. En línea similar, la STS 99/2019, de 26 de febrero, abandona las fundamentaciones subjetivas para reconocer que un elemento subjetivo del injusto, añadido al genérico dolo, no es, sin embargo, un requisito para apreciar la agravante.

En resumen, la situación tras la última sentencia citada (STS 99/2019, de 26 de febrero) es que la agravante de discriminación por razón de género tiene una fundamentación objetiva basada en la desigualdad que genera un estatuto social, antes que jurídico, del que deriva una discriminación para la mujer relacionada socialmente con el autor del delito y opera en supuestos en los que tal asimetría en la relación entre varón-autor y mujer-víctima concurra (Fundamento de Derecho Tercero) 
o "violencia familiar" en el Código penal, extiende de forma extraordinaria el concepto de "violencia" para incorporar la "violencia psíquica o psicológica-resta determinar si es lo mismo- o las microagresiones, e, incluso, inspirándose en textos internacionales, la denominada "violencia económica" -que, por cierto, rompe los límites del significado gramatical del término "violencia"-.

Finalmente, todas las cuestiones planteadas con anterioridad se materializan en un expreso interés de las instituciones por el estudio de la violencia de género, con la finalidad de adoptar las mejores de las medidas posibles para su erradicación. Este interés, sin embargo, no consigue los frutos esperados, al menos para el estudioso, porque cada institución ofrece los datos según sus propios criterios y utiliza su propia terminología. Las diferencias se detectan ya incluso en relación con el propio concepto, y plantean la necesidad de diferenciar claramente entre violencia de género ${ }^{22}$, violencia familiar, violencia contra la mujer y violencia doméstica, porque los documentos y estadísticas que estamos manejando para realizar esta investigación no siempre utilizan esta terminología y, cuando lo hacen, no tiene siempre el mismo significado ${ }^{23}$.

22 La especial protección -poco significativa, pero especial- que dispensan los delitos de violencia de género se explica, en nuestra opinión, por la concurrencia de dos procesos de victimización distintos, el primero de carácter social o no derivado del delito; el segundo fruto de una conducta delictiva. El primero de ellos coloca a la persona en una situación de vulnerabilidad fruto de valores y reglas de comportamiento aceptados socialmente. La violencia de género incide en un proceso de victimización social. Más ampliamente puede verse DE LA CUESTA AGUADO, P.M.: "Victimología y Victimología femenina: las carencias del sistema" en Victimología y Victimodogmática. Una aproximación al estudio de la víctima en el Derecho penal, de Reyna Alfaro (coord.), Lima (Perú), 2003, pp. 119 ss.

23 Así, por ejemplo, en los informes remitidos por el gobierno de Cantabria al parlamento de aquella Comunidad Autónoma, los datos aportados por la Policía Nacional se clasifican como "Violencia de género entre cónyuges o personas con relación análoga" dentro del epígrafe "malos tratos en el ámbito familiar" o "Delitos contra la libertad sexual"; los datos aportados por el equipo de la mujer y menor de la Guardia Civil se refieren, sin mayores distinciones a "asuntos relacionados con violencia de género"; la Oficina 
II. Pues bien, con independencia de la forma en que sea utilizada en otros documentos, a efectos de este artículo, denominaremos "violencia doméstica" a toda aquella que se desarrolla en el entorno de la familia y la convivencia. En este sentido, "violencia doméstica" sería el género al que pertenecen dos especies: la "violencia de género" -cualificada en función de las relaciones entre sujeto activo (hombre) y sujeto pasivo (mujer) en el ámbito de la pareja actual o pasada-y "violencia familiar", para hacer referencia a la que se produce en el ámbito doméstico excluyendo la de género. Esta es la distinción que, desde la LO 1/2004, de 28 de diciembre, de Medidas de Protección Integral contra la Violencia de Género, se ha impuesto en nuestro Código penal y, a partir de él, en Doctrina y Jurisprudencia. Sin embargo, tras la reforma del Código penal de 2015 -que, recordemos, introdujo el artículo 22.4 Código penal, como circunstancia agravante, la de cometer el delito por "razones de género" - quizá haya que replantearse los límites de la anterior diferenciación ${ }^{24}$.

\subsection{Sobre los delitos violentos}

I. Víctimas de delitos violentos son, en primer lugar, la que han padecido alguno de los delitos contra las personas (Títulos I a X del CP) o alguno de los delitos de robo con violencia (art. $242 \mathrm{CP}$ ) o el delito de extorsión (art. $243 \mathrm{CP}$ ) puesto que la víctima, en estos últimos supuestos, ha padecido, más allá de la privación de sus bienes, una situación de riesgo o perjuicio personal similar a los que estamos analizando ${ }^{25}$. También, evi-

de atención a la víctima de delitos violentos de Cantabria distingue entre "amenazas y coacciones; injurias y vejaciones; lesiones; maltrato; violencia de género y violencia doméstica, entre otros. La fiscalía discrimina por modalidades típicas, incluyendo "maltrato habitual 173.2 CP" y unos genéricos "amenazas $171 \mathrm{CP}$ y Coacciones $172 \mathrm{CP}$ " [sic].

24 Véase nota 21.

25 No valoraremos aquí otras modalidades delictivas de robos que pudieran cursar con fuerza en las cosas porque, tal y como está configurado el art. $238 \mathrm{CP}$, la fuerza típica no tiene funciones intimidatorias y porque, cuando, además, se use violencia o intimidación, se convertirá en robo con violencia 
dentemente, los delitos de atentados (arts. 550 y ss. CP) pueden ser ejecutados con violencia o intimidación, aunque las especiales características de las víctimas de estos delitos -mayoritariamente, en la práctica judicial, al menos, miembros de Fuerzas y Cuerpos de Seguridad del Estado- deberán ser tomadas en consideración a la hora de arbitrar medidas específicas de asistencia. En todos estos supuestos consideraremos que la violencia o la intimidación ejercidas son determinantes en el proceso de victimización primaria, razón por la que valorarán también en este epígrafe, sin perjuicio de que las conclusiones a las que lleguemos posteriormente en relación los delitos patrimoniales también les sean aplicables ${ }^{26}$.

II. Brevemente, y, como hemos dicho, sin ánimo de descripción exhaustiva, tomaremos como ejemplo para apreciar la entidad de este conjunto de delitos en el total de la criminalidad, el caso de la Comunidad de Cantabria durante el año 2016. Según los datos ofrecidos por el Instituto Nacional de Estadística, el número total de condenas dictadas por los Tribunales de Justicia en relación con delitos que implican un acometimiento físico con violencia o intimidación han sido, en esta Comunidad y en dicho año, 1.381. Estos datos no incluyen homicidios o lesiones producidas con ocasión de los delitos contra la seguridad vial. Respecto de la totalidad de las condenas dictadas en Cantabria

$\mathrm{y}$, por tanto, se incluirá en este epígrafe -no tomaremos, sin embargo, en consideración, el robo de vehículo a motor, porque las estadísticas de condenados no distinguen entre los delitos de hurto y de robo de uso, razón por la que los datos no son utilizables-. Tampoco tomaremos en consideración, aunque pueden ser delitos violentos, los delitos de terrorismo (Capítulo VII del Título XXII CP) y contra la Comunidad Internacional (Título XXIV $\mathrm{CP})$ por las características propias de las modalidades comisivas, porque suelen tener, cuando se producen, tratamiento específico y porque las posibles condenas por estos delitos no aparecen desglosadas en las estadísticas de condenados de INE (en Cantabria en 2016, no hubo ninguna sentencia condenatoria por estos delitos).

26 En cualquier caso, en los años 2013-2016 no se relaciona en las estadísticas de condenados del INE ninguna condena por el delito de extorsión en Cantabria. 
en el mismo periodo -que ascienden a 4.623- representan un $29,87 \%$, como se puede apreciar en la siguiente tabla:

Figura 1: Delitos que implican violencia o intimidación contra las personas en Cantabria en $2016^{27}$.

\begin{tabular}{|l|c|}
\hline Tipos delictivos & Total \\
\hline Homicidios y sus formas & 7 \\
\hline Lesiones & 863 \\
\hline Contra la libertad & 363 \\
\hline Contra la libertad sexual & 20 \\
\hline Robo con violencia & 85 \\
\hline Extorsión & 0 \\
\hline Total & $\mathbf{1 . 3 8 1}$ \\
\hline
\end{tabular}

Fuente: Estadisticas de condenados 2016. INE

A la vista de lo anterior, el número de víctimas de delitos violentos, aparentemente, puede ser importante, dado que un tercio de las condenas corresponden a estos delitos. En estos casos, los sujetos pasivos -víctimas-son objeto de conductas con un enorme impacto psicológico asociado a la agresión sufrida e independiente de los perjuicios o menoscabos físicos personales o materiales que origine el delito. Es por ello por lo que, desde una perspectiva victimológica, este grupo de víctimas requiere las mayores atenciones y preocupaciones por parte de las instituciones públicas. Conviene advertir que también deberían ser consideradas como víctimas de delitos violentos las de cualquier otro delito que, sin estar dirigido directamente a proteger bienes jurídicos personalísimos o el patrimonio de las personas, implique el uso de violencia o intimidación a las personas, cause o no resultados lesivo (por ejemplo, los arts. $522 \mathrm{CP}$ y $523 \mathrm{CP}$ ) $\mathrm{y}$, en general, aquellos que, al margen de los enunciados en este epígrafe, fueren cometidos utilizando violencia o intimidación

27 A lo largo del artículo, en numerosas ocasiones, ofreceremos datos de la situación en Cantabria, comunidad que ha sido seleccionada como ejemplo dadas sus características y el desarrollo de la OAV. 
sobre las personas, aun cuando tales medios comisivos no estén previstos expresamente como un requisito típico (entre otros y sin ánimo de exhaustividad, los del Capítulo V del Título XXI). Es especialmente importante considerar también como víctimas de estas modalidades delictivas a los familiares cercanos que se vean afectados personal o económicamente por el delito. Habida cuenta de la entidad del delito y la gravedad de la conducta y de sus efectos sobre las víctimas que los padecen -lesiones físicas o psíquicas, miedos, etc.-, las OAV deberán contar con medios específicos de asistencia y apoyo, de índole personal.

III. Hasta la reforma del Código penal de 2015, sujetos pasivos del art. $550 \mathrm{CP}$ eran las autoridades, sus agentes y funcionarios, concepto que, en la práctica, se solía restringir a quienes ejercen funciones de control del Orden Público (Fuerzas y Cuerpos de Seguridad del Estado). Aunque, teóricamente, la interpretación de estos conceptos debería hacerse a partir del art. 24 CP que define quiénes son autoridades y quiénes son funcionarios, lo cierto es que el concepto de autoridad o de funcionario que jurisprudencialmente se había venido utilizando a efectos del delito de atentado, era más restrictivo que el del art. $24 \mathrm{CP}$. La reforma de 2015, además de eliminar las faltas de nuestro Código penal y convertir gran parte de ellas en delitos leves, incluyó, expresamente, como sujetos pasivos de los delitos de atentados, resistencia y desobediencia, a nuevos grupos de funcionarios y autoridades administrativas, judiciales y políticas ${ }^{28}$,

28 Véase, por todos, JAVATO MARTÍN, A.M.: El delito de atentado. Modelos legislativos. Estudio histórico-dogmático y de Derecho comparado, Granada, 2005, p. 275. La diferente protección que reciben, a efectos del delito de atentado, en el art. 550.2 CP autoridades y funcionarios públicos ha sido puesta en tela de juicio por la Doctrina por las dificultades reales para distinguir entre autoridad, agentes y funcionarios, por carecer de justificación político criminal - pues no es el principio de autoridad lo que se protege- y porque la única justificación que cabe hay que buscarla en el (autoritario) origen histórico de la diferencia. Efectivamente, es el Código Penal de 1928 de la dictadura de Primo de Rivera, el que introduce por primera vez una específica protección de la "Autoridad"; distinción que el democrático Código Penal de 1932 abandonó, pero que la nueva dictadura franquista re-

Estudios Penales y Criminológicos,

vol. XXXIX (2019). ISSN 1137-7550: 403-454 -420- hitp://dx.doi.org/10.15304/epc.39.5970 
docentes y sanitarios, como eventuales sujetos pasivos de los delitos que ahora nos ocupan. Podría defenderse que esta ampliación era innecesaria, pues ya estaban incluidos en el concepto de funcionario a efectos penales definido en el art. $24 \mathrm{CP}^{29}$; aunque, también es cierto, que, salvo escasas excepciones, ni Doctrina ni Jurisprudencia extendía el delito de atentados más allá de funcionarios agentes de Fuerzas y Cuerpos de Seguridad del Estado ${ }^{30}$.

En cualquier caso, dada la diversidad caracterológica de los posibles sujetos pasivos del delito de atentado, sería necesario contar con datos más precisos que permitieran discriminar entre funcionarios y autoridades que pertenecen a las Fuerzas y Cuerpos de Seguridad del Estado y, por extensión, los que cumplen funciones en sentido genérico de control y vigilancia, y los

tomó en el Código Penal de 1944. De modo que podría afirmarse que se trata de una reminiscencia dictatorial que debería desaparecer en un sistema democrático (sobre la evolución histórica del concepto penal de autoridad y funcionario público puede verse DE LA CUESTA AGUADO, P. M.: "Sujetos y autores en los delitos de funcionarios: dos reflexiones teóricas con incidencia práctica", en Estudios penales en homenaje al profesor Rodrigo Fabio Suárez Montes, de J. G. Fernández Teruelo, M. González Tascón, S. Villa Sieiro (coords.), Oviedo, 2013, pp. 179 ss., especialmente, nota 3).

29 Sobre el alcance del art. 24 CP, véase OLAIZOLA FUENTES, I.: «Concepto de funcionario público a efectos penales», en Delitos contra la Administración Pública, Oñati, 1997, pp. 77 y ss. Específicamente para el delito de atentado, entre otros, véanse CUERDA ARNAU, M.L.: Los delitos de atentado y resistencia, Valencia, 2003, pp.41ss. y ROIG TORRES, M.: El delito de atentado, Cizur Menor, 2004, pp. 92 ss.

30 De nuevo, la LO 1/2019, de 20 de febrero, por la que se modifica la Ley Orgánica 10/1995, de 23 de noviembre, del Código Penal, para transponer Directivas de la Unión Europea en los ámbitos financiero y de terrorismo, y abordar cuestiones de índole internacional, "retoca" el concepto jurídicopenal de funcionario, en este caso, a efectos de delitos de cohecho, tráfico de influencias y malversación, lo que empieza a hacer dudar de la necesidad y corrección del artículo 24 del Código penal que, quizá, debería ser reformado para incorporar, expresamente si o cuando se considerara necesario, estos nuevos sujetos "funcionarios públicos", especialmente, los de carácter internacional -los demás, probablemente fuera innecesario-. Se podría aprovechar, además, para cuestionar la necesidad de mantener diferenciado del funcionario público a la autoridad. 
que no -algo que de las Estadísticas de condenados del INE no puede deducirse-. No obstante, lo cierto es que, en la actualidad, incluso tras la reforma de 2015, en la práctica jurisprudencial, la cuestión no ha cambiado sustancialmente y la inmensa mayoría de las sentencias condenatorias por delitos de atentados corresponden a los cometidos contra miembros de la Fuerzas y Cuerpos de Seguridad del Estado. Por otro lado, es preciso recordar también que no todos los delitos de atentados, resistencia y desobediencia implican violencia o intimidación, cuestión a la que tampoco es sensible la estadística, por lo que, los datos ofrecidos deben valorados con todos estos matices.

\subsection{Víctimas de violencia de género}

I. Entre las víctimas de delitos, el subgrupo de "víctimas de violencia de género" destaca por el interés que despierta en las Administraciones Públicas, lo que tiene como consecuencia que los datos disponibles sobre este fenómeno sean muy superiores a los disponibles sobre las víctimas de otros delitos. Característica identificativa de la violencia de género es la especial relación entre hombre y mujer (relación de afectividad o matrimonial, actual o anterior), en tanto que la violencia familiar tiene como elementos característicos la pertenencia al círculo familiar, convivencia o la vulnerabilidad. Pese a que ambas modalidades tienen un tratamiento jurídico penal cercano, los datos ofrecidos por las Administraciones Públicas difieren en entidad y calidad, por lo que, ahora, analizaremos exclusivamente los primeros; es decir, los relacionados con las víctimas de violencia de género.

A partir del art. 1 de la LO 1/2004, de 28 de diciembre, de Medidas de Protección Integral contra la Violencia de Gé$n e r o^{31}$, los delitos contra la "violencia de género" se han ido

31 Sobre la trayectoria histórico-legislativa de estos preceptos puede verse BOLEA BARDÓN, C.: "En los límites del Derecho penal frente a la violencia familiar y de género", en Revista electrónica de Derecho penal y Criminología 09-02 (2007), pp. 02:04 ss. Disponible en http://criminet.ugr. es/recpc/09/recpc09-02.pdf [citado: 20.09.2018].

Estudios Penales y Criminológicos,

vol. XXXIX (2019). ISSN 1137-7550: 403-454 -422- hitp://dx.doi.org/10.15304/epc.39.5970 
incrementando. En la actualidad, doctrinalmente se consideran delitos de violencia de género los contenidos en los artículos 153 CP; 148.4 CP; 171.4 CP; 172.2 Código penal y, aunque la razón de género no influye en la pena (y, por tanto, no sería un delito “de género"), el artículo 173.2 $\mathrm{CP}^{32}$. A estos preceptos, tras la

La autora se pregunta acerca de las razones por las que se puede sancionar más gravemente, hasta el punto de facilitar la entrada en prisión, al acometimiento físico leve realizado contra pareja o ex pareja, por razón de género. Afirma que ello se debe -el incremento de pena respecto de las penas que recibirían personas ajenas a los círculos de violencia de doméstica- al fenómeno de la violencia de género en su globalidad, al riesgo que corre la mujer tras un primer fenómeno de violencia manifiesta, y concluye que, en estos casos, entonces, una parte de la pena corresponde al riesgo futuro para la mujer (de muerte, de lesiones...). De hecho, afirma "el concepto de peligro futuro es la única base para castigar más severamente en estos casos los malos tratos (art. 153). Con el castigo desproporcionado de estos actos, en realidad, a la pena que les correspondería se le suma una "pena" añadida por la peligrosidad futura que parecen implicar. Tal "pena", como fácilmente puede deducirse no tiene carácter de pena en sí, sino de medida de seguridad" (p.02:20). Es una sugerente explicación, sin lugar a dudas, la de BOLEA BARDÓN, que implicaría la magnífica noticia de que hombres y mujeres en el seno de la sociedad -en sus relaciones sociales- y en el seno de la familia -en sus relaciones familiares y de pareja- ostentan la misma posición, son iguales en derechos y deberes -no solo ante la ley, sino, de hecho- $y$, por tanto, el tratamiento penal por actos iguales entre iguales merece idéntica pena y, "el exceso", puede atribuirse a la peligrosidad. Lamentablemente esto no es así; por el contrario, la mujer padece, de forma previa y permanente, un proceso de victimización social en el que se le coloca en una posición inferior y más débil que al hombre. De esta posición social se generan mayores dificultades para la participación en el dialogo social y, en caso de relaciones de pareja, incluso de sometimiento o de mayores cargas, lo que aboca a que las dificultades para defenderse o romper la relación violenta sean mayores. En nuestra opinión son estas, y no otras, las razones por las que las agresiones en el ámbito de las relaciones de pareja protegen más a la mujer que a un extraño o al miembro masculino de la pareja. Más ampliamente, sobre esta postura puede verse DE LA CUESTA AGUADO, P.M.: "El concepto de "violencia de género" de la LO 1/2004 en el sistema penal: fundamento, trascendencia y efectos", en Revista de derecho y proceso penal, n. $^{\circ} 27,2012$, pp. 37-52.

32 Aunque este precepto plantea dudas a la Doctrina, porque, en él, el tratamiento que reciben los sujetos del círculo de violencia de género y los sujetos del círculo de violencia doméstica es idéntica, como pone de manifiesto, SAN MILLÁN FERNÁNDEZ, B.: El delito de maltrato habitual, Valencia, 
reforma de 2015 del Código penal, habría que sumar, de alguna forma, todos aquellos a los que se haya aplicado la agravante de género contenida en el art. 22.4 CP. Pues bien, a pesar de que existe una cierta unanimidad doctrinal acerca de la extensión de los "delitos contra la violencia de género", en el sentido expuesto, cuando se revisan los documentos o informes de las diversas instituciones o entidades que de una forma $u$ otra se acercan al fenómeno, lo cierto es que la terminología, el ámbito de los delitos relacionados con la violencia de género y otras cuestiones similares son de lo más diverso.

Para empezar, detengámonos en la siguiente tabla, en la que se relacionan los delitos que se analizan en los Informes sobre la violencia de Género en Cantabria a los que hemos hecho referencia con anterioridad ${ }^{33}$. Obsérvese cómo cada una de las instituciones que aportan datos utiliza un concepto de delitos contra la violencia de género distinto $\mathrm{y}$, en consecuencia, los datos ofrecidos también difieren.

Figura 2

\begin{tabular}{|l|l|l|l|l|}
\hline Modalidad & Policía* & Fiscalía* & CGPJ** & \\
\hline Homicidio & & & $\mathrm{X}$ \\
\hline Art. 148.4 (lesiones) & & $\mathrm{X}$ & $\mathrm{X}$ \\
\hline Art. 153.1 (maltrato singular) & $\mathrm{X}$ & $\mathrm{X}$ & $\mathrm{X}$ \\
\hline Art. 173.2 (maltrato habitual) & $\mathrm{X}$ & $\mathrm{X}$ & $\mathrm{X}$ & \\
\hline Art. 172.ter.2 (acoso) & & $\mathrm{X}$ & $* * *$ & \\
\hline Art. 171.4 (amenazas) & $\mathrm{X}$ & $\mathrm{X}$ & $* * *$ & \\
\hline Art. 172.2 (coacciones) & $\mathrm{X}$ & $\mathrm{X}$ & $* * *$ & \\
\hline Art. 173.1 (Integridad moral) & & $\mathrm{X}$ & $\mathrm{X}$ & \\
\hline Aborto & & & $\mathrm{X}$ & \\
\hline
\end{tabular}

2017, p. 68. Sobre los círculos de sujetos implicados en violencia de género y violencia doméstica, véase MANJÓN-CABEZA OLMEDA, A.: en Derecho penal español. Parte especial (I), de F.J. Álvarez García (Dir.), $2^{\mathrm{a}}$ ed., Valencia, 2011. cit., p. 493.

33 Véase nota 11. 


\begin{tabular}{|l|l|l|l|l|}
\hline Lesiones al feto & & & $\mathrm{X}$ \\
\hline Libertad sexual & $\mathrm{X}$ & $\mathrm{X}$ & \\
\hline
\end{tabular}

Fuentes: Elaboración propia a partir de los documentos que se relacionan a continuación.

* Informe del Gobierno de Cantabria sobre Violencia de Género 2016.

** Informe "Datos de denuncias, procedimientos penales y civiles registrados, órdenes de protección y medidas de protección y seguridad solicitadas en los juzgados de violencia sobre la mujer (JVM) y sentencias dictadas por los órganos jurisdiccionales en esta materia", del Consejo General del Poder Judicial. En estos informes trimestrales emitidos por el "Observatorio contra la Violencia Doméstica y de Género" del Consejo General del Poder Judicial, con carácter trimestral, el criterio de discriminación parece ser que los sujetos activo y pasivo mantengan la relación propia de la "violencia de género".

*** Los datos se ofrecen bajo el genérico epígrafe de "delitos contra la libertad".

Los datos más completos los ofrece el CGPJ, pese a la simplificación que comporta la unificación de varias modalidades típicas de distinto contenido bajo el epígrafe único de "delitos contra la libertad". En cualquier caso, resulta interesante resaltar cómo ya el CGPJ configura un concepto de "violencia de género" menos vinculada a los tipos penales introducidos por la LO 1/2004, de 28 de diciembre, de Medidas de Protección Integral contra la Violencia de Género y más descriptiva de un fenómeno social que se puede manifestar en numerosos tipos delictivos, si bien, parece que aún, en 2016, circunscrita a la relación de pareja que con reiteración hemos venido definiendo.

II. En cuanto a la interpretación del concepto de "violencia de género" en relación con los preceptos contenidos en la LO 1/2004 de 28 de diciembre, de Medidas de Protección Integral 
contra la Violencia de Género ${ }^{34}$, y a partir de la definición de "violencia de género" establecido en su artículo 1, algunas Audiencias Provinciales, siguiendo a una línea jurisprudencial del Tribunal Supremo, han entendido que tales delitos deben aplicarse "exclusivamente" cuando la agresión del hombre contra su mujer responda a "razones de género", es decir, a motivos discriminatorios o "machistas", lo que, en la práctica, significa excluir la aplicación automática de los tipos de género en los denominados supuestos de "agresiones mutuas" y cuando ambos sujetos se encuentran en "situación de igualdad". Más recientemente, esta posición parece haber sido abandonada, ante las críticas doctrinales recibidas, reformulándose en el sentido de que, cabe excluir la aplicación de los delitos "de violencia de género" cuando se constata la existencia de "otra finalidad" -en las sentencias que lo han acogido, cometer delitos contra el patrimonio de la víctima de violencia ${ }^{35}$. En cualquier caso, los tribunales de Cantabria no se han sumado a esta última postura $\mathrm{y}$, generalmente, aplican automáticamente los tipos cuando concurren las relaciones típicas entre hombre y mujer ${ }^{36}$.

Las últimas sentencias del Tribunal Supremo ${ }^{37}$, por su parte, parecen empezar a aceptar que el concepto de "violencia de género" no es tanto un concepto normativo, a efectos pena-

34 Los delitos "de violencia de género" fueron introducidos de forma claramente diferenciada de los delitos "de violencia familiar", con modalidades típicas específicas y pena ligeramente más grave por la LO 1/2004 de 28 de diciembre, de Medidas de Protección Integral contra la Violencia de Género que, o bien modificó los ya existentes, o introdujo nuevas modalidades típicas. Los preceptos (y tipos) afectados por esta ley son los artículos 153 CP; 148.4 CP; 171.4 CP y 172.2 CP. Es decir, todos los que hemos calificado como delitos de "violencia de género en sentido estricto" - no se incluye el art 173.2 CP que fue introducido por la LO 15/2003, de 29 de septiembre de medidas concretas en materia de seguridad ciudadana, violencia doméstica e integración social de los extranjeros y no fue afectado por la reforma de 2004-.

35 Véase nota 21.

36 Así, entre otras muchas, ST Jugado de lo Penal n. 5 (Santander), 278/2015, de 27 de julio, Fundamento de Derecho $2^{\circ}$.

37 Véase nota 21.

Estudios Penales y Criminológicos,

vol. XXXIX (2019). ISSN 1137-7550: 403-454 -426- hitp://dx.doi.org/10.15304/epc.39.5970 
les, cuanto un concepto descriptivo de un fenómeno social que da lugar a diversas manifestaciones delictivas también fuera de las relaciones de pareja. El concepto de "violencia de género" rompe así los estrechos márgenes de la "violencia en el ámbito de la pareja" y abre las puertas a la comprensión global del fenómeno. Desde luego hay mucho trayecto que recorrer, pero, si es así, nos encontraremos con que determinados delitos, en los que la víctima sea mujer y el victimario, hombre, siempre serán delitos de violencia de género.

II. El problema de los significados latentes, por un lado, y las imprecisiones propias del lenguaje cuando no se utilizan términos estrictamente jurídicos, por otro, se pone de manifiesto en los sucesivos Informes Anuales sobre la Violencia de Género remitidos por el Gobierno de Cantabria al Parlamento Autonómico, en cumplimiento de lo dispuesto en el artículo 15.2 la Ley de Cantabria 1/2004, de 1 de abril, Integral para la prevención de la violencia contra las mujeres y la protección a sus vícti$\operatorname{mas}^{38}$. La falta de uniformidad terminológica utilizada por las distintas instituciones con responsabilidad en la materia, cuyos datos estadísticos son incorporados a dichos informes, dificulta el estudio. Esta diversidad terminológica se manifiesta en lo siguiente:

1. En cuanto a la designación de las partes implicadas en los correspondientes delitos (sujetos activos, sujetos pasivos): mientras que es común la utilización del término "víctima", la designación del "victimario" -término que no se utiliza- diverge según las instituciones implicadas. Así, la Guardia Civil y la Policía Nacional se refieren al sujeto activo (eventual) como

38 Actualmente están publicado los informes correspondientes a los años 2015, http://mujerdecantabria.com/wp-content/uploads/2018/01/informe-Violencia-de-genero-Cantabria-2015.pdf [citado:18.08.2018] y 2016, http:// mujerdecantabria.com/wp-content/uploads/2018/05/Violencia-de-generoCantabria-2016.pdf [citado:18.08.2018]. El informe correspondiente al año 2017, ha sido admitido a trámite por el Parlamento Autonómico, según comunicación publicada en el Boletín Oficial de Cantabria de 23 de julio de 2018. 
"agresor"; los datos procedentes del Poder Judicial los nombra como "denunciados" y la Unidad de valoración integral del Instituto de Medicina Legal de Cantabria se refiere a ellos como "imputados". La utilización de una u otra fórmula no es baladí, porque la "pareja" de términos "víctima-agresor" va preñada de connotaciones emocionales e implica un juicio del hablante sobre los designados, poco compatibles con la presunción de inocencia, allí donde haya de ser respetada. Otros términos, como el de denunciante-denunciado, en informes emitidos por instituciones que han de aplicar la ley penal y en momentos previos a la sentencia, probablemente sean preferibles -lo que en relación con ámbitos de asistencia a las víctimas podría ser sustituido por "usuarias/os"-.

En cualquier caso, la unificación terminológica para designar a los sujetos implicados facilitaría la comprensión de los informes, racionalizaría el informe, el estudio y el análisis -en la medida en que se utilizaran términos moral e ideológicamente asépticos- y repondría a los sujetos a su condición de personas al dejar de ser calificados por su rol en un evento: la víctima pasaría a ser usuaria, lo que implicaría, respecto de ella misma un avance incluso nominal ("dejó de ser víctima para no serlo más") y el victimario aparecería ante las instituciones públicas, ante el proceso penal y ante la sociedad como un sujeto cuya conducta está sometida a un juicio con todas las garantías, sin sanciones sociales previas. Creo que la racionalización en el uso de los términos tendría, además, el efecto de permitir integrar en la protección de las víctimas a aquellos sectores sociales que en estos momentos se levantan y claman contra las medidas legales y asistenciales adoptadas contra la violencia de género con el "argumento" de que es un fenómeno inventado y de que es utilizado por las mujeres de forma torticera. Frente a la irracionalidad -en el sentido de ausencia de análisis racional de la realidad, bien por desconocimiento, bien por miedo- de quienes así se manifiestan, la estrategia correcta es la racionalidad, en este caso, mediante la utilización de términos asépticos (y jurídicos, que para eso están) aceptados como razonables en todos los 
ámbitos de la criminalidad y garantistas de los derechos de las personas sometidas a juicios procedimentalmente justos.

La anteriormente analizada no es la única disarmonía terminológica que se ha podido detectar en los Informes que ahora analizamos. Así, en cuanto a ciertos grupos de víctimas, la "Unidad de valoración integral del Instituto de Medicina Legal de Cantabria" distingue -y solo ella- entre "víctimas y menores". Aunque tal distinción puede significar un avance, pues advierte de que los menores también son víctimas de violencia doméstica, invita a la confusión, pues en relación con los menores que viven en entornos familiares en los que hay violencia de género, en el sentido de los informes, se pueden detectar tres situaciones distintas:

a) menores que han sufrido directamente la conducta típica, es decir, que, además de la violencia padecida por la madre, ellos mismos también han padecido violencia por parte del mismo victimario (en este caso, violencia familiar)

b) menores que no han sufrido personalmente la violencia por parte del victimario, pero que han estado presentes cuando la madre/mujer la ha padecido, y, en este sentido, también serían víctimas del delito.

c) menores que ni han padecido ni han presenciado conducta típica alguna, pese a estar integrados en el círculo familiar.

2.- En relación con los delitos objeto de denuncia, enjuiciamiento o tratamiento de cualquier índole. El mayor de los problemas se plantea en cuanto a la interpretación de la genérica expresión "orden de alejamiento" ${ }^{39}$ por las siguientes razones:

39 Así, la Policía Nacional ofrece datos únicamente sobre quebrantamiento de órdenes de alejamiento y la Guardia Civil aporta información sobre "quebrantamientos de órdenes de alejamiento" a los que identifica como "quebrantamientos de condena". Por su parte, los informes del Observatorio de la Violencia Doméstica y de Genero del CGPJ sí distinguen quebrantamiento de penas y quebrantamientos de medidas, aunque no se pronuncian 
a.- Impide distinguir entre las órdenes que se imponen como pena en la sentencia de aquellas otras que se imponen como medida de seguridad.

b.- Exigiría definir previamente qué se entiende por "orden de alejamiento", si se refiere a la prohibición del artículo 48.2 CP de aproximarse a la víctima u otras personas que determine el Juez o a la del artículo 48.3 $\mathrm{CP}$, de comunicarse con la víctima u otras personas que determine el Juez. La genérica designación no permite identificar la prohibición concretamente impuesta -o si se imponen las dos simultáneamente-.

c.- En cualquier caso, tampoco permite identificar a la persona cuya protección se pretende (¿mujer? ¿hijos? ¿otros familiares?). Pero, sería muy interesante conocer este dato, especialmente, cuando la o las prohibiciones afecten también a los hijos o a otras personas en situación de riesgo (familiares, por ejemplo) ${ }^{40}$.

expresamente sobre a qué tipo de prohibición se refieren. Véanse el Informe de 2016 a que hace referencia la nota anterior, p. 20 y el documento "Series violencia de género" junto a otros documentos publicados por el Observatorio contra la Violencia de Doméstica y de Género del CGPJ, disponibles en http://www.poderjudicial.es/cgpj/es/Temas/Violencia-domestica-y-degenero/Actividad-del-Observatorio/Datos-estadisticos/La-violencia-sobre-la-mujer-en-la-estadistica-judicial--Primer-trimestre-de-2018 [citado: 18.08.2018].

40 En otro orden de cuestiones, pero siguiendo con diferencias en la metodología en el tratamiento de los datos, en relación con los Informes del Gobierno de Cantabria a que hemos venido haciendo referencia, la Guardia Civil ofrece datos sobre las órdenes de protección concedidas en relación con las denuncias recibidas, a diferencia de la Policía Nacional, aunque esta sí contiene un desglose por delitos -a diferencia de la Guardia Civil. Por su parte, los datos aportados por el CGPJ tampoco siguen los mismos criterios, aunque en el documento "Violencia sobre la mujer por partido Judicial. Primer trimestre 2018, se distingue entre "Lesiones y Malos Tratos del Art. 153 del CP"; "Lesiones y Malos Tratos del Art. 173 del CP" y "Lesiones y Malos Tratos del Art. 148 y ss. del CP”. El panorama se complica más aún cuando entran en juego los datos aportado por la "Oficina de asistencia a víctimas de delitos violentos" cuya terminología se aparta de las anteriores (así, por ejemplo, en la p.23 del informe 2016 hace referencia de "actuaciones por los 
3.- En relación con la cuantificación de las agresiones, la única conclusión posible es que no cuadran las cuentas. Baste un ejemplo: según los datos aportados por el CGPJ en el Informe del Gobierno de Cantabria 2016, el total de atestados policiales recibidos en Cantabria asciende a 501. Sin embargo, el total de denuncias recibidas por la Policía Nacional y la Guardia Civil ascienden a 727. Estos datos parecen indicar que en torno al $31 \%$ de las denuncias presentadas en relación con los que ambos cuerpos denominan "Violencia de género" se pierden por el camino, aunque no constan las razones -y podría ser muy interesante saberlas-.

Pero, si nos centramos en el número de detenidos por ambos cuerpos de seguridad, el total de detenidos en relación con estos delitos asciende a 575, de donde cabe preguntarse: ¿cómo es posible que el Poder Judicial solo reconozca haber recibido 501 atestados policiales? Con el más posibilista de los ánimos, podríamos imaginar dos posibles razones para tal desfase de 74 detenidos que parece que no fueron puestos a disposición judicial: 1) que se hayan recibido denuncias a finales del año 2015 que dieron lugar a atestados recibidos por el Poder judicial ya en el año 2016. Ahora bien, si se hace una ponderación anual, resulta que se harían una media de 1,57 detenidos al día; lo que valorando dos días de traslado del atestado con detenido daría un total de en torno 4 los atestados que se "descabalgan" con el cambio de año -muy distantes de los 74 detenidos-. 2) La otra alternativa posible sería que hubiera más de un detenido por cada atestado, pero, teniendo en cuenta que hoy por hoy las parejas suelen ser monógamas, no parece que tampoco pueda explicar el desfase ${ }^{41}$.

siguientes delitos" maltrato" (57) y "violencia de género" (56) o "delito leve ordinario" (3). En definitiva: resulta sumamente complejo analizar la efectiva protección que reciben las mujeres que padecen violencia de género.

41 No nos podemos detener, en este momento, en otros grupos de delitos bien por su reducida o nula presencia jurisprudencial, bien porque solo parcialmente pueden integrarse en el grupo de víctimas que estamos analizando. Entre ellos cabría destacar las víctimas de discriminación y de delitos de odio o las víctimas de delitos contra el Derecho de gentes (genocidio, lesa humanidad) y de crímenes de guerra. 
En definitiva, aunque las Administraciones Públicas y las Fuerzas y Cuerpos de Seguridad del Estado dedican especial atención al estudio del fenómeno de la violencia de género -o contra la mujer, según la diferente terminología utilizada-, lo cierto es que se aprecia poca coordinación entre las diversas entidades e, incluso en un mismo documento, entre las instituciones implicadas.

Los informes de las instituciones a las que nos estamos refiriendo, que tienen competencia sobre el control y/o la sanción de las conductas delictivas o de la protección y asistencia a las víctimas, son muy necesarios porque ofrecen datos que permitirán entender el fenómeno de esa concreta criminalidad. Ahora bien, hemos tenido ocasión de reseñar algunas cuestiones que impiden que cumplan la función prevista; la objetividad de los informes se ve empañada por el uso de términos que no son asépticos y tampoco jurídicos -ni criminológicos- y que implican juicios de valor, y no hemos podido constatar que sean eficaces para mejorar la asistencia a las víctimas.

\section{Víctimas de delitos contra el patrimonio de las personas}

El interés de las instituciones públicas encargadas del control de la criminalidad y/o su persecución y sanción, es bastante menor, al menos, en cuanto a los estudios, informes y medios materiales destinados a la asistencia a las víctimas de estos delitos, en relación con los delitos contra el patrimonio de las personas (que no implican violencia o intimidación) y pese a que, año tras año, copan los primeros puestos en las Estadísticas de Condenados del $\mathrm{INE}^{42}$, el interés que suscita este grupo de víctimas, sobre todo, cuando no padecen violencia personal, es limitado. En relación con las necesidades de asistencia a las víctimas de estos delitos que no implican ni violencia ni intimi-

42 Porcentualmente, este grupo de delitos representa el 29,02\% del total de condenados judicialmente en la Comunidad de Cantabria y aproximadamente el 36\% del total en España, en 2016. 
dación, el aspecto que mayor refuerzo necesita en la actualidad -más allá de la garantía de los derechos que reconocen el Estatuto de la Víctima y otras normas de nuestro Ordenamiento Jurídico- es el de la asistencia en su relación con el sistema judicial penal $^{43}$.

A estos efectos, ha de tenerse en cuenta que para el ciudadano que ve mermado su patrimonio de forma delictiva y, desde su percepción subjetiva, injusta ${ }^{44}$, la investigación y proceso penales pueden ser angustiosos, amedrentadores y de difícil comprensión, además de dilatados en el tiempo. La víctima -sujeto pasivo del delito- tiene que denunciar, lo que genera miedo y estrés; miedo a posibles represalias por parte del delincuente, estrés al enfrentarse al poderoso aparato estatal y toda la parafernalia policial. Además, puede verse privado de sus bienes durante todo el proceso, bien porque estén a disposición judicial, bien porque no estén disponibles en absoluto y tendrá que acudir a declarar como testigo, bajo amenaza de incurrir en delito, lo que le exigirá desplazamientos, tiempos y esfuerzo, someterse a situaciones inquisitoriales y perderse entre laberínticos pasillos de edificios desconocidos e imponentes. En definitiva, la víctima -sujeto pasivo- de un delito contra el patrimonio de las personas físicas se enfrenta a un proceso penal que también para él puede ser frustrante y generar un nuevo proceso de victimización. En estos supuestos, el coste personal y económico para mantener activo el proceso penal es alto y de sus declaraciones e impulso depende el devenir del proceso que, en numerosas ocasiones, en caso contrario, quedará sobreseído.

43 En este ámbito se han realizado algunas experiencias en materia de mediación penal. Puede verse, en este sentido, PASCUAL, E./ RIOS, J./SÁEZ, C./ SÁEZ, R.: "Una experiencia de mediación penal", en Boletín criminológico 102 (2008), http://www.boletincriminologico.uma.es/boletines/102.pdf, [citado: 13.03.2019].

44 También desde una perspectiva objetiva, por supuesto. Pero lo que quiero recalcar ahora es la posición personal de la víctima del delito frente al hecho padecido: lo esencial en este caso es que las instituciones que le protegen han fallado y ella -la víctima- ha padecido una injusticia. 
Para cualquier persona ajena, los Juzgados son lugares incomprensibles, especialmente para quienes, al no ser parte en el proceso, no cuentan con el apoyo e información de un abogado. Esta circunstancia -el hecho de no ser parte en el proceso penal y no contar con abogado- es relativamente habitual, sobre todo en los delitos patrimoniales de escasa entidad. Los efectos descritos podrían dar lugar a procesos de victimización secundaria y, en cualquier caso, a la desconfianza del ciudadano respecto de la Justicia penal y al descrédito del sistema judicial. Por ello, las OAV deberían contar con medios para paliarlos; por ejemplo, con Páginas Web propias, que, además de los fríos datos de localización y contacto, o reproducción de la literalidad de los preceptos legales sobre sus funciones, incluyeran información útil para la víctima, con una imagen cercana y acogedora y respondieran a cuestiones prácticas tales como: dónde aparcar, cómo llegar a la sala donde tendrá lugar la audiencia, dónde comer por los alrededores, cómo pedir asistencia jurídica gratuita, etc. ${ }^{45}$. Se trata, obsérvese, de medidas simples y baratas, pero que, una vez garantizada la necesaria seguridad de los edificios, faciliten a las víctimas de los delitos su inmersión en el mundo policial y judicial, sobre todo, en este último. Estas medidas, además, se extenderán y beneficiarán a todas las víctimas de delitos, cualquiera que sea el delito padecido, evidentemente.

\section{Víctimas de delitos que utilizan las tecnologías de la infor- mación o Internet}

I. La Sociedad de la Información hace tiempo que llegó al mundo de criminalidad para quedarse ${ }^{46}$. Sin embargo, los cambios sociales son más lentos que los cambios en la criminali-

45 Sobre las OAV puede verse TAMARIT SUMALLA, J.M.: "La reparación y el apoyo a las víctimas", en El estatuto de las víctimas de delitos. Comentarios a la Ley 4/2015, de J.M. Tamarit Sumalla, C. Villacampa Estiarte y M. Serrano Masip (coord.), Valencia, 2015, pp. 330 y ss. En el mismo libro, de diversos autores, cuestiones relacionadas con este problema.

46 Puede verse MIRÓ LLINARES, F.: "La oportunidad criminal en el ciberespacio. Aplicación y desarrollo de la teoría de las actividades cotidianas para la prevención del cibercrimen", en RECPC 13-07 (2011), pp. 07:1- 
dad y en este ámbito, la protección y asistencia a las víctimas de los ciberdelitos -los delitos que se cometen a través de Internet, redes sociales o cualquier fórmula de acceso al ciberespacio o mundo virtual- es aún muy precaria. Según los datos del Instituto Nacional de Estadística, en 2016, el 84\% de la población española de entre 16 y 74 años ha usado Internet, datos que se reducen al $82,7 \%$ en Cantabria ${ }^{47}$. En relación con los menores en España, en 2016 se calculaba que el 94,9 \% manejan ordenadores $^{48}$

La siguiente tabla compara los datos de uso de Internet entre España y Cantabria según los datos ofrecidos por Encuesta sobre Equipamiento y Uso de Tecnologías de Información y Comunicación en los Hogares (Año 2017) ${ }^{49}$.

Figura 3

\begin{tabular}{|l|l|l|}
\hline Actividad realizada & España & Cantabria \\
\hline Usa Internet & $84,6 \%$ & $82,7 \%$ \\
\hline Usa habitualmente Internet & $69 \%$ & $77,3 \%$ \\
\hline Compra por Internet & $40 \%$ & $46,3 \%$ \\
\hline
\end{tabular}

Fuente: Elaboración propia a partir de Nota de prensa sobre Encuesta sobre Equipamiento y Uso de Tecnologías de Información y Comunicación en los Hogares. Año 2017. Instituto Nacional de Estadística 5 de octubre de 2017.

07:55. Disponible en http://criminet.ugr.es/recpc/13/recpc13-07.pdf [citado:24.03.2019].

47 Con carácter general sobre el incremento de los ciberdelitos, puede verse, con bibliografía, el reciente trabajo de MEŠKO, G.: "One some aspects of Cybercrime and Cybervictimization", en European Journal of Crime, Criminal Law and Criminal JUstice 26 (2018), pp. 189-199.

48 Estudio sobre la cibercriminalidad en España, 2017, del Ministerio del Interior, p.16. Disponible en

http://www.interior.gob.es/documents/10180/5791067/ Estudio+Cibercriminalidad +2016 .pdf/456576b2-9ce8-4f3c-bbccca0dbf3bb3cf [citado:30.08.2018]

49 "Encuesta sobre Equipamiento y Uso de Tecnologías de Información y Comunicación en los Hogares. Año 2017", disponible en https://www.ine.es/ prensa/tich 2017.pdf [citado:30.08.2018]. La encuesta fue realizada en los tres primeros meses de 2017, de donde se deduce que los datos de refieren al último trimestre de 2016 y primer trimestre de 2017. 
Esta breve muestra pone de manifiesto que la generalidad de los ciudadanos interactúa en Internet y, por tanto, son susceptibles de ser víctimas de delitos, ya sea contra bienes personalísimos -libertad, identidad digital, honor, intimidad...-, ya sea contra intereses patrimoniales - donde la modalidad de conductas tendentes a obtener un lucro originando un perjuicio son numerosas (y va a más)-. En este sentido, puede ser interesante repasar los datos ofrecidos por el Informe Norton sobre Ciberdelitos: el impacto humano ${ }^{50}$, realizado entre el 2 y el 22 de febrero de 2010, que, aunque lejano en el tiempo, es el más específico en cuanto a las modalidades delictivas y que puede servirnos, al menos, para constatar que el mundo virtual es tan policromático, en lo que a delitos cometidos se refiere, como el mundo real.

Figura 4

\begin{tabular}{|l|l|}
\hline Delitos padecidos & Porcentaje mundial \\
\hline Virus & $51 \%$ \\
\hline Estafas & $10 \%$ \\
\hline Phishing & $9 \%$ \\
\hline Usurpación de perfiles en redes sociales & $7 \%$ \\
\hline Fraudes tarjetas bancarias & $7 \%$ \\
\hline Acoso sexual & $7 \%$ \\
\hline
\end{tabular}

Fuente: Elaboración propia a partir de los datos contenidos en el Informe Norton sobre Ciberdelitos: el impacto humano

50 Dejaremos al margen de este trabajo las conductas que se dirigen a atacar páginas web de administraciones u organismos públicos. Según el Informe Norton sobre ciberdelitos, el $65 \%$ de los adultos de todo el mundo ha sido objeto de ciberdelitos. Vid. Informe Norton sobre Ciberdelitos: el impacto humano, realizado entre el 2 y el 22 de febrero de 2010. Disponible en:

http://www.symantec.com/content/en/us/home homeoffice/media/pdf/cybercrime_report/Norton_Spanish-Human\%20Impact-A4_Aug11.pdf [citado: 30.08 .2018$]$. 
Más cercano en el tiempo y en el espacio, el Estudio sobre la cibercriminalidad en España, 2016 ${ }^{51}$, del Ministerio del Interior, concluye que el total de procesos de victimización por "cibercriminalidad" ascendió en España, ese año, a 54.446, de los que el 54,44\% fueron varones y el $45,66 \%$ mujeres y, en $2017^{52}$, se produjo un incremento de un 14,64\%, elevándose a la cifra de 62.419 , de los que el 54,5\% fueron varones. Esta es, precisamente, una de las especificidades de estos procesos de victimización, que afectan prácticamente por igual a hombres y a mujeres -algo similar y, por tanto, también en este sentido, excepcional, sucede con los delitos de odio. Estos niveles de equiparación se mantienen en todas las modalidades delictivas excepto en los delitos contra la libertad o indemnidad sexual, en los que las víctimas mujeres ascienden al 64\%, en 2016, y al 63\%, en 2017. Sin embargo, en cuanto a las detenciones -lo que nos indicaría el sexo de los victimarios- el $77 \%$ son varones, en el conjunto de los delitos cometidos. Ahora bien, este dato también se ve alterado cuando se trata de delitos contra la libertad o indemnidad sexual, en los que el número de los delitos cometidos por hombres se eleva hasta el 97\%, en 2016, o el 94\%, en 2017.

Figura 5. Víctimas de delitos cometidos utilizando Tecnologías de la Información

\begin{tabular}{|l|l|l|l|}
\hline Año & Total & Mujeres & Hombres \\
\hline 2016 & 54.446, & $45,66 \%$ & $54,44 \%$ \\
\hline 2017 & 62.419, & $45,5 \%$ & $54,5 \%$ \\
\hline
\end{tabular}

Fuente: Elaboración propia con datos del Ministerio del Interior

51 Estudio sobre la cibercriminalidad en España, 2016, del Ministerio del Interior, disponible en:

http://www.interior.gob.es/documents/10180/5791067/ Estudio+Cibercriminalidad+2016.pdf/456576b2-9ce8-4f3c-bbccca0dbf3bb3cf [citado:30.08.2018].

52 Estudio sobre la cibercriminalidad en España, 2017, del Ministerio del Interior, disponible en: http://www.interior.gob.es/documents/10180/7146983/ Estudio+Cibercriminalidad+2017.pdf/a937823d-8af5-4baa-86fa-7f085f$7 \mathrm{cac} 07$ [citado:24.03.2019]. 
A la vista de lo anterior y, en resumen, en los delitos cometidos utilizando Tecnologías de la Información, se constata un cierto equilibrio por razón del sexo de las víctimas, salvo en los delitos contra la libertad e indemnidad sexual, donde, de nuevo, las víctimas femeninas superan a las masculinas. Por el lado de los victimarios son mayoritariamente varones -si bien, con mayor participación de mujeres que en los delitos no cibernéticos-, excepto, también, en los delitos contra la libertad sexual, donde son varones la inmensa mayoría.

Los responsables de la protección y apoyo a las víctimas deben ser conscientes de esta realidad para adecuar la asistencia y las medidas dirigidas a la protección de las víctimas de delitos contra la libertad e indemnidad sexual -con una evidente incidencia de la cuestión de género-, a esta realidad.

II. Aunque la ciberdelincuencia y la cibervictimización han sido objeto de interés creciente y se ha afirmado que podría superar en volumen a los delitos cometidos en el espacio físico ${ }^{53}$, los resultados de los estudios publicados no son concluyentes. Las especiales características del ciberespacio inciden, efectivamente, de forma directa en la comisión del delito, en las formas de comisión y en la investigación del delito ${ }^{54}$, pero está por determinar hasta qué punto las especiales condiciones de tiempo, lugar y modus operandi generan sobre cibervíctimas nuevos y distintos efectos -respecto de los producidos por el delito en el mundo real-y, por tanto, nuevas y distintas necesidades ${ }^{55}$. Con la certeza de tales carencias de conocimiento, cualquier decisión de apoyo a las cibervíctimas debe partir del reconocimiento de que los usuarios no son conscientes de las amenazas de Internet, se ven afectados por un sesgo de optimismo y no tienen sufi-

53 MEŠKO, G.: "One some aspects of Cybercrime and Cybervictimization", cit., p.195.

54 Puede verse MIRÓ LLINARES, F.: El cibercrimen. Fenomenología y criminología de la delincuencia en el ciberespacio, Madrid, 2012, passim.

55 Véase, en sentido similar MEŠKO, G.: "One some aspects of Cybercrime and Cybervictimization", cit., pp.192 s. 
ciente capacidad técnica para protegerse. Esto significa que los riesgos que asumen los usuarios son muy altos.

Especial mención requiere el aspecto económico de la protección frente a ciberdelitos en Internet, tales como estafas, robo de identidad, malware, etc. -no ataques de tipo personal como amenazas, acosos o similares-. El coste de la ciberseguridad es demasiado alto para una gran mayoría de usuarios que, además, suelen contar con varios dispositivos electrónicos ${ }^{56}$. Esta situación, unida a la general falta de habilidades (y conocimientos) tecnológicos, tienen una especial incidencia en el miedo al ciberdelito ${ }^{57}$ posterior al proceso de victimización que padecen las cibervíctimas - miedo, por otro lado, equiparable al que padecen las víctimas de delitos en el mundo real, pero que, por lo antedicho, presenta características especiales-. Por otro lado, aunque el delito es "virtual" y se realiza en un "mundo virtual", los efectos son físicos y tienen real incidencia en las personas y su entorno ${ }^{58}$. Para el diseño de las medidas de apoyo a las cibervíctimas se deben tener en cuenta estas circunstancias. En cualquier caso, una correcta asistencia ha de asumir, primero, la reactancia psicológica -entendida, siguiendo a MEŠKO, como la resistencia por parte de internauta a aceptar medidas de seguridad que percibe como una limitación de la libertad en Internet- $y$, segundo, que los usuarios en Internet, como cualquier persona, sienten la normal resistencia al cambio, propia del comportamiento humano, que, en un entorno tan cambiante, tiene especial trascendencia. Todo ello incide en la falta de con-

56 Al-Nemrat, A./ Jahankhani, H./ Preston, D.: "Cybercrime Victimisations/ Criminalisation and Punishment", en Global Security, Safety, and Sustainability, Belin-Heidelberg, 2010, pp. 129 ss.

57 Sobre el concepto de ciberdelito, puede verse, entre otros, pero resumidamente CHANG, L.: Cybercrime in the Greater China Region, CheltenhamNorthampton, 2012, pp. 22 ss.

58 En este sentido se afirma que el ciberdelito no es una fantasía, sino que el daño y los perjuicios que origina son reales. Puede verse en CHAMBERSJONES, C. (con HILlMAN, H.), Financial Crime and Gambling in a Virtual World. A new frontier in Cybercrime, Cheltenham-Northampton, 2014, p. 63. 
ciencia de la necesidad de adoptar medidas de autoprotección y el desconocimiento acerca de cuáles adoptar, en su caso.

En cuanto a los posibles efectos adversos, el INFORME NORTON, relaciona como principales efectos que padecen las víctimas de ciberdelitos los siguientes:

- Sentimiento de impotencia, porque los delincuentes son anónimos y/o residen en el extranjero.

- Tendencia a autoinculparse, sintiéndose responsables de lo sucedido.

- Sentimiento de frustración: el estudio destaca que en muy pocas ocasiones las cibervíctimas piden ayuda y, cuando lo hacen, la ayuda que reciben no es adecuada o no está correctamente orientada, lo que genera una enorme frustración porque ha supuesto para la cibervíctima una pérdida de tiempo y los logros obtenidos con ella han sido escasos. Esta sensación se ve incrementada por el desconocimiento de "medios de ayuda" y las dificultades, en su caso, para restablecer la "reputación on line".

Resta, finalmente, detenerse en una última cuestión que no es analizada por los estudios y encuestas de victimización porque no está derivada del delito, pero que, en gran manera, incide en el proceso de victimización: me estoy refiriendo al generalizado desconocimiento por parte de los usuarios de Internet y Tecnologías de la Información (especialmente, redes sociales y similares) acerca de qué conductas son delictivas y qué conductas son peligrosas -en el sentido de que generan riesgos de ser víctima de un ciberdelito-. $\mathrm{Si}$, en el mundo real, el desconocimiento de qué conductas son delictivas no es extraordinariamente preocupante -razón por la que la apreciación de errores de prohibición es también extraordinariamente reducida-, el desconocimiento entre los usuarios de las $T I C$ 's de qué está penalmente prohibido (o de qué conductas pueden ser delictivas) 
es mayúsculo, porque se trata de delitos de muy nueva factura ${ }^{59}$ y muy complejos, lo que dificulta gravemente la comprensión por parte de los ciudadanos -y de los juristas-. A ello se une la realidad de que la sociedad cada vez se divide más entre nativos digitales y los que no lo son, pero, los primeros por su juventud y su ausencia de formación -cuando no una enorme malformación obtenida sin ninguna garantía de veracidad- desconocen cuándo sus conductas son (o pueden ser) delictivas; cuándo son sujetos pasivos de delitos $-\mathrm{y}$, en tal caso, víctimas- y cuándo están corriendo graves riesgos. En cuanto a los segundos, la formación en nuevas tecnologías puede ser escasa y, en consecuencia, la vulnerabilidad, importante.

III. En la situación descrita, los retos que presenta la asistencia a las cibervictimas son mayores y las posibles soluciones, probablemente, algo más complejas que las propias de los delitos en el mundo físico. Por un lado, las cibervíctimas presentan características y necesidades comunes a las víctimas de delitos ordinarios, pero, además, presentan perfiles específicos, por su mayor vulnerabilidad y por el alto riesgo de revictimización o de renuncia a las posibilidades que las Tecnologías de la Información ofrecen por miedo al delito ${ }^{60}$. En este sentido, algunas de las

59 Ejemplo de ello es la regulación de los delitos contra la propiedad intelectual y, específicamente, los arts. 270 y $271 \mathrm{CP}$, cuya actual -y complejaredacción típica es de 2015, tras haber sido, también, reformado en 2003 y 2010.

60 Sobre el miedo al delito y la incidencia en la victimización entre otrs muchos puedes verse, con bibliografía, CASADO TOLEDO, FJ./ MIRO LLINARES, F.: “¿Nos parecen más inseguros los ciberlugares después de un ciberataque?, en International e-Journal of Criminal Science 12 (2018), disponible en http://www.ehu.eus/ojs/index.php/inecs/article/view/19689/17541 [citado: 20.11.2018], pp. 2-3, para quienes "[e]1 miedo al crimen es definido como un estado mental específico basado en una estructura evaluativa de eventos delictivos". NARVÁEZ MORA, M.: "El miedo al delito no es un supuesto de victimización indirecta", en International e-Journal of Criminal Science 3 (2009), Artículo 3, p. 13, disponible en http://www.ehu. eus/ojs/index.php/inecs/issue/view/28 [citado: 20.11.2018], recuerda, sin embargo, que "[e]n cierta medida la precaución que el miedo aconseja se convirtió en un reductor efectivo del riesgo: quienes se sienten con más riesgos potenciales, acaban teniendo menos riesgos estadísticos". Esta constata- 
funciones específicas que podrían asumir las OAV en relación con estas víctimas irían encaminadas a prevenir futuros delitos y a orientar en la adopción de medidas de autoprotección -lo que, por otro lado, no es exclusivo de este grupo de víctimas, sino que es especialmente importante también para las víctimas de violencia de género y, posiblemente, familiar-. En este sentido las OAV podrían tener encomendadas las siguientes funciones:

a) Funciones de información

La gestión y difusión de la información, como hemos adelantado, debería ser uno de los pilares de la actividad de las OAV, al margen, por supuesto, de otras reglamentariamente previstas. Entre otros temas, podrían tener interés los siguientes aspectos:

1) información sobre las posibilidades de interponer denuncia y las especiales dificultades que presenta la persecución de los ciberdelitos.

2) específicamente, podrían aportar información sobre instituciones públicas o privadas que pudieren ayudar a solventar los problemas derivados del desconocimiento técnico de las víctimas, así como ofrecer indicaciones sobre los pasos a seguir, bien mediante folletos, bien mediante información disponible en Internet.

3) información a los ciudadanos, en general, y a las cibervictimas, en particular, sobre medidas de autoprotección y otras medidas de prevención del delito. Especial importancia podrían tener, entre estas posibles medidas, aquellas destinadas a difundir la información sobre ataques masivos o generalizados y posibles medidas preventivas con la finalidad de reducir al máximo la "reacción en cadena" y el número de víctimas ${ }^{61}$.

b) Funciones de coordinación entre instituciones con fines de protección

ción es sumamente interesante para diseñar estrategias de protección de las víctimas.

61 Sobre la "Wiki prevención del Cibercrimen", véase CHANG, L.: Cybercrime in the Greater China Region, cit., p.170. 
En cuanto a las actividades de coordinación con otras instituciones, cobraría especial importancia la relacionada con las instancias investigadoras y empresas o particulares que padecen ataques o que son instrumentos o, de alguna forma, se ven implicados - por ejemplo, con bancos para la prevención de delitos que impliquen ataques o amenazas a cuentas corrientes, robo de identidad, etc.- . timización)

c) Funciones de prevención de delitos (y procesos de vic-

Finalmente, aunque quizá ello excediera, en principio, de las funciones propias de las $\mathrm{OAV}$, podría informarse -mediante folletos en papel o en Páginas Web u otra serie de medidas informativas- acerca de qué conductas muy habituales entre los ciudadanos son constitutivas de delito, pues son muchos, sobre todo jóvenes, los que desconocen que conductas como leer el correo electrónico ajeno, utilizar las claves de otros, acceder a información ajena en redes sociales o en dispositivos electrónicos, sin autorización, suplantar la identidad virtual o difundir imágenes de personas, también sin autorización, podría ser constitutivo de delito.

\section{Víctimas de delitos contra la seguridad vial}

Según los datos del INE, en España, el número de condenas contra la seguridad vial ha sido de 86.200 en 2016 y 86.879 en 2017, siendo los delitos con mayor número de condenas $(21,9 \% \text { del total en } 2017 \text { y un } 23,8 \% \text { en } 2016)^{62}$. Estos datos ratifican la tendencia de los últimos años y los delitos que reciben mayor número de condenas, según el INE, son los delitos contra la seguridad vial. Bien es cierto que estas modalidades

62 Notas de prensa correspondientes a los años 2016 y 2017 proporcionadas por INE. Disponibles en https://www.ine.es/prensa/ec_am_2017. pdf y https://www.ine.es/prensa/ec_am_2016.pdf, respectivamente [citadas:21.10.2018]. Durante el año 2016, en Cantabria ha habido 1.050 condenados por delitos contra la seguridad vial, lo que representa un $22,71 \%$ del total. 
delictivas no tienen por qué producir víctimas mortales o lesiones, pero habrá que tener en cuenta que sí pueden provocar estos resultado -o daños-. Pero, además, las víctimas de estos delitos contra la seguridad vial, presentan peculiaridades específicas ${ }^{63}$ como consecuencia de la situación de peligro que han padecido, Así, podemos distinguir entre víctimas directas, que padecen personalmente el delito y que serían aquellas personas que, como consecuencia de la conducta típica sufran lesiones o daños materiales, y víctimas indirectas, que serían los familiares y allegados de los anteriores, pero muy especialmente, de quienes han fallecido como consecuencia de la infracción penal, aunque, este concepto no coincide con el de "víctima indirecta" a efectos del Estatuto de la Víctima.

Algunas de las medidas sugeridas con anterioridad para otros grupos de víctimas serían también de enorme utilidad para este grupo, entre otras, la información precisa sobre cómo relacionarse con el sistema penal, ayudando a resolver problemas prácticos tales como "dónde están los Juzgados", "qué se va a encontrar la víctima o afectado cuando vaya al Juzgado y cómo afrontarlo", "dónde aparcar", etc., Evidentemente todas estas son medidas de coste reducido, en las que lo más importante es una correcta planificación y gestión de la información, pero que, sin duda, tendrá un efecto beneficioso en la percepción de las víctimas de la Justicia ${ }^{64}$.

63 En principio, podría pensarse que este grupo de delitos no genera víctimas, porque los artículos 379 y siguientes, son delitos de peligro, y como tal, en principio, no es necesario que produzcan lesiones para que la conducta sea típica. Sin embargo, el INE obtiene los datos del Registro de penados, donde las condenas calificadas bajo este epígrafe incluyen aquellos supuestos en los que por aplicación del art. $382 \mathrm{CP}$, los peligros se han materializado en daños, lesiones y muertes, lo que impide saber con exactitud cómo se han contabilizado.

64 Todo ello, por ejemplo, al margen de otras funciones propias de la OAV como informar acerca de posibles ayudas sociales, etc. 


\section{Delitos relacionados con el incorrecto funcionamiento de la Administración Pública y de la Administración de Justicia}

El incorrecto funcionamiento de la Administración Pública $^{65}$, aunque no revista caracteres delictivos, genera situaciones que, desde la perspectiva de quienes las padecen, pueden ser similares a un proceso de victimización, por cuanto la superioridad de la Administración Pública respecto del administrado es tan manifiesta que puede llegar a intimidar y a generar sentimientos de miedo, impotencia o vulnerabilidad -muy similares a los que genera "el miedo al delito"-y que, además, puede generar perjuicios patrimoniales, importantes pérdidas de tiempo, estrés, etc. Pese a las similitudes con otros procesos de victimización primaria, en estos casos nos encontramos con dos órdenes de dificultades que es preciso enunciar expresamente:

a) Sobre el equilibrio entre las partes implicadas en el delito

Al ciudadano le resulta muy costoso, en términos personales y económicos, iniciar un procedimiento administrativo o penal, ya sea contra órganos, autoridades o funcionarios públicos administrativos o judiciales. A las dificultades habituales a las que hacíamos referencia en epígrafes anteriores -miedo a represalias, desconocimiento del mundo judicial y de cuestiones jurídicas, entre otras- se suma la indudable desigualdad entre particular (perjudicado/víctima) y funcionario público (magistrado, autoridad...). Junto a ello, y fruto de la posición de supremacía del funcionario público, en numerosas ocasiones, el ciudadano se encuentra con serias dificultades para iniciar y proseguir un

65 Son numerosos los delitos que plantean, en este punto, cuestiones similares. Así los de los títulos XIX y XX del Código penal, que, aun constituyendo modalidades típicas de diversa factura, tienen en común que las víctimas son personas que se han visto perjudicadas por la actuación irregular de órganos administrativos o judiciales y por autoridades y funcionarios públicos. Pero las reflexiones que ahora expondremos también podrían afectar a algunas otras modalidades típicas contenidas en otros Títulos ajenos a los de este epígrafe, por ejemplo, algunos preceptos del Capítulo V del Título XXI, cuando hayan sido realizados en el ejercicio de la función pública, así, entre otros, el art. $531 \mathrm{CP}$ o el art. $541 \mathrm{CP}$. 
procedimiento penal, entre otras, dificultades para encontrar un abogado que apoye sus pretensiones. Tales dificultades pueden incidir en el sentimiento de injusticia, desamparo y miedo de quien se encuentra inmerso en un proceso de victimización y afectar seriamente a la credibilidad de las propias instituciones públicas $\mathrm{y}$, en último término, del sistema político democrático.

b) Sobre el reconocimiento de la condición de víctima previo a la declaración de culpabilidad

Por otro lado, es preciso ser consciente de las gravísimas consecuencias que para un funcionario público tiene ser acusado en vía policial o judicial de haber cometido un delito relacionado con la corrupción. Ciertamente los perjuicios que para el victimario (posible sujeto activo de un delito) implica su persecución penal no deben incidir en la protección de las víctimas; por el contrario, un Estado Democrático de Derecho exige, demanda, necesita, que los delitos cometidos en el seno de las instituciones públicas sean dilucidados ante un órgano judicial de forma pública y transparente y, en caso de ser constitutivo de delito, sus autores sean razonables y legalmente sancionados. Ahora bien, también es cierto que una querella o una denuncia por prevaricación o delito similar puede ser un arma poderosa en manos de ciudadanos que pretenden ostentar posiciones de privilegio o que, simplemente, están enfadados por la correctísima y honesta actuación del funcionario público que no está dispuesto a ceder ante sus pretensiones. De modo que las reflexiones que se van a hacer en este epígrafe -como en todos los demás- no significa prejuzgar la conducta ni del funcionario público, autoridad u órganos administrativo o judicial, ni la del ciudadano o administrado. Por el contrario, se ponen de manifiesto ambos aspectos del problema para intentar buscar soluciones razonables para los perjudicados/víctimas sin generar injustas cazas de brujas para el funcionario público.

La primera consecuencia que cabe extrae de estas reflexiones es que, en relación con estos delitos, considerar como víctima a una persona antes de que exista un pronunciamiento 
penal con todas las garantías, es especialmente peligroso y tribunales y Administración Pública han de ser cautelosos a la hora de realizar pronunciamientos que lleven aparejados prejuicios, como sucede con el concepto de víctima y con todos aquellos que supongan una lesión de la presunción de inocencia. Dicho esto, y, en segundo lugar, cabe convenir que, como se ha advertido, la posición del administrado debe ser reforzada por razones de transparencia y de credibilidad del sistema democrático y judicial-penal. No es fácil, sin embargo, diseñar estas medidas en abstracto y, con los medios con los que actualmente cuentan las OAV, podría parecer que estamos entrando en el mundo de la ciencia-ficción. Pero, que las OAV pudieran facilitar información jurídica, apoyo psicológico e incluso ayuda y asistencia para contratar abogados y/o procuradores de otros lugares -ajenos por tanto a cualquier tipo de "presión ambiental" (o, simplemente, de "presión")- serían, francamente, imprescindibles.

c) Sobre los perfiles de las víctimas

En cuanto a los administrados eventualmente perjudicados, y en tal sentido "víctimas", pueden aún, a grandes rasgos, distinguirse dos perfiles paradigmáticos: por un lado, podemos encontrar al ciudadano, individuo sin mayores cualificaciones, que actúa a título personal y con unos medios extraordinariamente escasos, si se compara con los recursos de la Administración Pública y, por otro, a corporaciones, empresas o particulares que, desde una posición de fortaleza económica o política, se enfrentan, también, a la Administración Pública; sujetos que reunirían las características del "delincuente de cuello blanco" y que cuentan con medios, recursos económicos y/o políticos y, desde luego, mayor agilidad que la Administración Pública para conseguir sus fines.

En relación con el primero de los perfiles, hay que valorar, a efectos de arbitrar medidas de asistencia específicas, aquellos supuestos en los que los afectados por las decisiones de la Administración Pública son un número considerable de personas. Esto sucede, por ejemplo, en las expropiaciones forzosas para obras 
públicas o en las concentraciones parcelarias, que se prolongan durante años -decenios- y que, por las particulares características de estos procesos y la debilidad de los afectados, son coto abonado para corruptelas, abusos o corrupciones por parte de algún funcionario público o autoridad administrativa -aunque el procedimiento en su conjunto se ajuste a la legalidad-. Por otro lado, la protección penal frente a desmanes que contiene el art. $541 \mathrm{CP}^{66}$ tiene escasísima virtualidad práctica ${ }^{67}$. De hecho, los Tribunales penales evitan su aplicación con el argumento de que las irregularidades que darían lugar a la conducta típica han sido posteriormente subsanadas en vía contencioso-administrativa, lo que como argumento jurídico es bastante débil, pues el delito se consumaría con la realización de la conducta típica por la autoridad o funcionario público, con independencia de que, posteriormente, la propia Administración Pública o los Tribunales de Justicia revirtieran la situación antijurídica creada. Aunque también puede darse el supuesto contrario: grupos de afectados por una ley que se organizan para evitar los perjuicios que de ella derivan y recurren los actos administrativos querellándose contra los funcionarios públicos que, en el ejercicio de sus funciones, deben aplicarla.

Estos supuestos a los que nos referimos en el párrafo anterior presentan especiales dificultades (desde la perspectiva de la asistencia a las víctimas). En primer lugar y como hemos advertido, la consideración como víctima del administrado, no debería iniciarse hasta que, con todas las garantías se hubieran iniciado actuaciones judiciales -sin perjuicio, por supuesto, de las medidas de apoyo específicas a cualquier ciudadano en orden a iniciar procesos penales-. Por ello quizá fuera conveniente

66 El art. $541 \mathrm{CP}$ contiene el denominado "delito de expropiación arbitraria" según el cual "[1]a autoridad o funcionario público que expropie a una persona de sus bienes fuera de los casos permitidos y sin cumplir los requisitos legales, incurrirá en las penas de inhabilitación especial para empleo o cargo público de uno a cuatro años y multa de seis a doce meses".

67 Más ampliamente DE LA CUESTA AGUADO, P.M.: El delito de expropiación arbitraria, ed. Tirant lo Blanch, Valencia, 2016. 
plantearse la necesidad de que la propia Administración Pública contara con oficinas de apoyo a los administrados, con la autonomía suficiente para cumplir una eficaz labor de información y asistencia cuando estos se consideraren perjudicados por la eventual actuación delictiva de un funcionario público o autoridad. Las ventajas para reforzar la confianza en el Ordenamiento Jurídico son evidentes. Las dificultades que entraña, también. En segundo lugar, una vez que, con garantías, se abre un proceso penal, la asistencia a los perjudicados/víctimas del delito exigiría contar con protocolos de actuación de tomen en consideración la eventual concurrencia masiva de perjudicados.

d) Sobre la valoración jurídico-penal de la entidad de la conducta típica

Quizá una de las razones de la necesidad de diseñar estrategias de apoyo a los administrados ante conductas delictivas realizadas por autoridades o funcionarios públicos -atendiendo a su diferente posición en sus relaciones con la Administración Pública y en función de cada uno de los perfiles que hemos identificado en el párrafo anterior- estriba en que los tipos contenidos en el Código penal dan un tratamiento homogéneo a las conductas prevaricadoras, relacionadas con la corrupción o similares con independencia de la entidad y efectos de la resolución o actuación administrativa, de los sujetos afectados y del número de perjudicados o víctimas. Así, por ejemplo, el Código penal trata prácticamente igual al funcionario público o autoridad que dicta una resolución prevaricadora que origina, por ejemplo, un perjuicio económico leve que a quien se ve privado de su vivienda habitual por una expropiación forzosa, que le origina un gravísimo perjuicio patrimonial e, incluso, una alteración de su vida habitual considerable. Según la lógica del Derecho penal y las finalidades de protección de estos delitos, esto podría ser aceptable -sin perjuicio de que, por supuesto, los tribunales tienen instrumentos para matizar la resolución o individualizar la pena-, pero ello no significa que, desde la perspectiva de los afectados por tales delitos -y, en ese sentido, víctimas-, el tratamiento deba ser idéntico. 
Las sucesivas reformas del Código penal muestran una tendencia al incremento de las penas en algunos de los delitos contra la Administración de Justicia y Pública -en paralelo, por otro lado, con el incremento de la presión penal generalizada desde 1995-, pero, podría dar la impresión de que tal incremento punitivo está especialmente orientado a los grandes casos de corrupción -que, al final, son los que llegan a conocimiento de la opinión pública-, pero que olvidaría o sería inadecuado para los numerosos casos de "pequeños delitos" -"pequeñas" prevaricaciones, "pequeño" tráfico de influencias, "pequeños" cohechosque, con independencia de la cuantía de la pena, al menos por razón de un menor desvalor de resultado, merecería una pena menor que los "grandes" delitos relacionados con grandes casos de corrupción.

Desde la perspectiva de las víctimas, sin embargo, es precisamente este grupo de "pequeña corrupción" el que requiere, quizá, una mayor atención por la probable mayor vulnerabilidad de las víctimas de los delitos y sus mayores dificultades para tomar parte y defender sus intereses en el proceso penal. En este ámbito resta mucho trabajo por hacer, se necesita, como advertíamos anteriormente, conocimiento, planificación y medios. Pero, esta perspectiva pone de manifiesto la importancia de la asistencia a nuevos grupos de víctimas para la sociedad, para el Ordenamiento jurídico y para el sistema penal. Específicamente desde la perspectiva del Derecho penal, la satisfacción de estas muy básicas necesidades de las víctimas sería muy beneficiosa, pues ayudaría a racionalizar y legitimar la intervención penal, en la medida en que la "satisfacción" de las víctimas no se deja exclusivamente en manos de la sanción penal y, por tanto, la presión social (basada en el miedo al delito sobre el Legislador y el propio Derecho penal) sería menor, lo que facilitaría retomar la senda de las buenas leyes penales -esto es, las que respetan los principios de un sistema penal democrático y, además, son técnicamente correctas-. 


\section{Epílogo}

Hace décadas que empezaron a extenderse por el territorio español las Oficinas de Atención a las Víctimas que cuentan ya con un extenso soporte legal. Por la importancia de su función para el sistema penal es necesario reflexionar acerca de sus funciones en relación con las necesidades de las víctimas para generar nuevas ideas y detectar déficits.

En las últimas décadas, tras las fuertes críticas recibidas por las Teorías de la Pena para legitimar la intervención penal, el resarcimiento y satisfacción de las víctimas de delitos se ha convertido en un nueva y potente vía para legitimar el Derecho penal. La cultura de la victimidad exige al Legislador cada vez mayor atención a las necesidades -objetivas y subjetivas- de las víctimas, lo que se traduce en que la sociedad parece que exige una mayor intervención penal y el incremento constante de las penas. En esta irracional deriva, se reclama -y el Legislador se suma a ello con excesiva alegría- que el Derecho penal abandone los estrechos márgenes de los hechos y el garantismo, para proteger de forma cada vez mayor los sentimientos de quienes son o se sienten víctima. Pero ni el delito ni las penas son medios adecuados para satisfacer las necesidades, materiales o no, de las víctimas. De ahí la importancia de arbitrar normativamente medidas jurídicas, sociales, psicológicas, pero también de organizar y ofrecer otras medidas más modestas, pero más prácticas y cercanas a los ciudadanos, que eviten la revictimización, apoyen a las víctimas en sus relaciones con la Justicia y faciliten su (re) encuentro con el sistema penal y con la sociedad. En este sentido han de ser entendidas estas modestas reflexiones.

\section{Bibliografía}

AL-NEMRAT, A./JAHANKHANI, H./ PRESTON, D.: "Cybercrime Victimisations/Criminalisation and Punishment", en Global Security, Safety, and Sustainability, BerlinHeidelberg, 2010, pp. 55-62. 
BOLEA BARDÓN, C.: "En los límites del Derecho penal frente a la violencia familiar y de género", en Revista electrónica de Derecho penal y Criminología 09-02 (2007), pp. 02:01-02:26. Disponible en http://criminet.ugr.es/recpc/09/recpc09-02.pdf [citado: 20.09.2018].

CASADO TOLEDO, F.J./ MIRO LLINARES, F.: “¿Nos parecen más inseguros los ciberlugares después de un ciberataque?, en International e-Journal of Criminal Science 12 (2018), pp. 1-25. Disponible en http://www.ehu.eus/ ojs/index.php/inecs [citado: 20.09.2018].

CHAMBERS-JONES, C.: Financial Crime and Gambling in a Virtual World. A new frontier in Cybercrime, Cheltenham-Northampton, 2014.

CHANG, L.: Cybercrime in the Greater China Region, Cheltenham-Northampton, 2012.

CUERDA ARNAU, M.L.: Los delitos de atentado y resistencia, Valencia, 2003.

DE LA CUESTA AGUADO, P.M.: "Victimología y Victimología femenina: las carencias del sistema", en Victimología y Victimodogmática. Una aproximación al estudio de la víctima en el Derecho penal, de L. Reyna Alfaro (coord.), Lima (Perú), 2003, pp.119-142.

"El concepto de "violencia de género" de la LO 1/2004 en el sistema penal: fundamento, trascendencia y efectos", en Revista de derecho y proceso penal, n. ${ }^{\circ} 27,2012$, pp. 37-52.

- "Sujetos y autores en los delitos de funcionarios: dos reflexiones teóricas con incidencia práctica", en Estudios penales en homenaje al profesor Rodrigo Fabio Suárez Montes, de J. G. Fernández Teruelo, M. González Tascón, S. Villa Sieiro (coords.), Oviedo, 2013, pp. 173-194.

-El delito de expropiación arbitraria, ed. Tirant lo Blanch, Valencia, 2016.

DE VICENTE MARTÍNEZ, R.: El delito de robo con violencia o intimidación en las personas, Valencia, 2002.

HASLAM, N.: "Concept creep: Psychology's expanding concepts of harm and pathology", en Psychological Inquiry, n. 27, 2016, pp. 1-17. 
HENDERSON, L.: “The Wrong's of Victim's Rights", en Scholarly Works (1985), paper 871. Disponible en https:// www.repository.law.indiana.edu/cgi/viewcontent. cgi?referer=https://www.google.es/\&httpsredir=1\&articl $\mathrm{e}=2922$ \& context $=$ facpub [citado:13.11.2018].

JAVATO MARTÍN, A.M.: El delito de atentado. Modelos legislativos. Estudio histórico-dogmático y de Derecho comparado, Granada, 2005.

LAURENZO COPELLO, P.: "La violencia de género en la Ley Integral. Valoración político-criminal", en RECPC 07-08 (2005), pp. 08:1-08:23. Disponible en: http://criminet. ugr.es/recpc/07/recpc07-08.pdf [citado: 20.09.2018].

MANJÓN-CABEZA OLMEDA, A.: Derecho penal español. Parte especial (I), de F.J. Álvarez García (Dir.), 2ª ed., Valencia, 2011.

MEŠKO, G.: "One some aspects of Cybercrime and Cybervictimization", en European Journal of Crime, Criminal Law and Criminal JUstice 26 (2018), pp. 189-199.

MIRÓ LLINARES, F.: El cibercrimen. Fenomenología y criminología de la delincuencia en el ciberespacio, Madrid, 2012.

— "La oportunidad criminal en el ciberespacio. Aplicación y desarrollo de la teoría de las actividades cotidianas para la prevención del cibercrimen", en RECPC 13-07 (2011), pp. 07:1-07:55. Disponible en http://criminet.ugr.es/recpc/13/recpc13-07.pdf [citado:24.03.2019] .

NARVÁEZ MORA, M.: "El miedo al delito no es un supuesto de victimización indirecta", en International e-Journal of Criminal Science 3 (2009), pp. 1-40. Disponible en http:// www.ehu.eus/ojs/index.php/inecs/article/view/261/258 [citado:17.03,2019].

OLAIZOLA FUENTES, I.: «Concepto de funcionario público a efectos penales», en Delitos contra la Administración Pública, de A. Asúa Batarrita, Oñati, 1997, pp. 77-84.

PASCUAL, E./ RIOS, J./ SÁEZ, C./ SÁEZ, R.: "Una experiencia de mediación penal", en Boletín criminológico 102 
(2008). Disponible en http://www.boletincriminologico. uma.es/boletines/102.pdf [citado: 13.03.2019].

QUINTERO OLIVARES, G.: Comentarios a la parte especial del Derecho penal, de G. Quintero Olivares (Dir.), 10 ed., Cizur Menor, 2016.

ROIG TORRES, M.: El delito de atentado, Cizur Menor, 2004.

SAN MILLÁN FERNÁNDEZ, B.: El delito de maltrato habitual, Valencia, 2017.

SÁNCHEZ TOMÁS, J.M.: La violencia en el Derecho penal, Barcelona, 1999.

TAMARIT SUMALLA, J.M.: "La reparación y el apoyo a las víctimas" en El estatuto de las víctimas de delitos. Comentarios a la Ley 4/2015, de J.M. Tamarit Sumalla, C. Villacampa Estiarte y M. Serrano Masip (coord.), Valencia, 2015, pp. 305-354.

VILLACAMPA ESTIARTE, C.: "Pacto de estado en materia de violencia de género: ¿más de lo mismo?”, en RECPC 2004 (2018), 2 jun, pp. 1-38. Disponible en http://criminet. ugr.es/recpc/20/recpc20-04.pdf [citado: 20.02.2019]. 